IAN KOROLKOVAS

Sistema de monitoramento de transmissão de

TV digital em redes convergentes

heterogêneas

São Paulo 
IAN KOROLKOVAS

\title{
Sistema de monitoramento de transmissão de TV digital em redes convergentes heterogêneas
}

\author{
Dissertação apresentada à Escola Politécnica \\ da Universidade de São Paulo para obtenção \\ do título de Mestre em Engenharia
}

São Paulo 
IAN KOROLKOVAS

\title{
Sistema de monitoramento de transmissão de TV digital em redes convergentes heterogêneas
}

\author{
Dissertação apresentada à Escola Politécnica \\ da Universidade de São Paulo para obtenção \\ do título de Mestre em Engenharia \\ Área de concentração: Sistemas Digitais \\ Orientador: Prof. Dr. Edison Spina
}

São Paulo 
Este exemplar foi revisado e alterado em relação à versão original, sob responsabilidade única do autor e com a anuência de seu orientador.

São Paulo, 15 de setembro de 2007

Assinatura do autor

Assinatura do orientador

\section{FICHA CATALOGRÁFICA}

Korolkovas, lan

Sistema de monitoramento de transmissão de TV digital em redes convergentes heterogêneas / I. Korolkovas. - ed.rev. São Paulo, 2007.

$83 \mathrm{p}$.

Dissertação (Mestrado) - Escola Politécnica da Universidade de São Paulo. Departamento de Engenharia de Computação e Sistemas Digitais.

1.Gerência de redes 2.Televisão digital (Monitoramento) 3.Redes de Computadores I. Universidade de São Paulo. Escola Politécnica. Departamento de Engenharia de Computação e Sistemas Digitais. II.t. 
Dedico esta dissertação à minha mãe, que sempre desejou minha vitória, me apoiando e incentivando para meu crescimento. 


\section{Agradecimentos}

Ao Professor Doutor Edison Spina, por sempre se mostrar disposto a ajudar, especialmente na orientação neste trabalho.

Ao Professor Doutor Denis Gabos, pela oportunidade e grande ajuda e participação e comprometimento na elaboração deste trabalho.

Ao Professor Titular Wilson Vicente Ruggiero, por muito ter me ensinado durante esses anos, contribuindo para o meu crescimento científico e intelectual.

À Professora Doutora Itana Stiubiener, meu sincero agradecimento por ter me recebido no LARC. Obrigado por todos os incentivos, conselhos e oportunidades.

Às Professoras Doutoras Regina Melo Silveira e Graça Bressan pelas oportunidades de projetos e aprendizado com experimentos de laboratório de redes de computadores.

À Comissão Européia integrada ao INSTINCT (IST-1-507017-IP-Oe) por ter patrocinado este trabalho.

À Fundação Fundação de Apoio à Universidade de São Paulo pela concessão de bolsa e auxílio financeiro.

Aos meus grandes amigos Christiane e Daniel por toda ajuda, apoio e irmandade. Que tudo que aprendemos nesses anos em redes seja usado para nunca perdermos nossa comunicação.

Aos amigos Samuel e Gustavinho pela grande amizade e ótimo relacionamento que partilhamos.

Aos meus colegas de baia Edivaldo e Raoni, pelo agradável convívio durante todos esses anos.

À todos pesquisadores e colegas do LARC pela troca de experiência e por tornar deste laboratório um ótimo ambiente de trabalho.

À minha irmã Filly, por sempre acreditar em mim e sempre se dispor a me ajudar. Obrigado pela grande ajuda na revisão deste trabalho. 
Ao meu grande amor, Aline, por estar sempre do meu lado e tornar minha vida tão feliz.

À todas outras pessoas que, de alguma maneira, também contribuíram para que este trabalho se realizasse. 
"Ao adentrar a porta do aprender a aprender vislumbram-se os grandes horizontes do saber. E tendo por ela passado, os caminhos a trilhar nos levam ao êxtase do conhecimento, da auto-realização e da felicidade." Valdomiro Korolkovas, meu pai. 


\section{Resumo}

A grande evolução nos sistemas de comunicação, relacionados à transmissão de conteúdo multimídia nas redes de comunicação de dados e de transmissão de TV, demanda soluções de gerência da qualidade de serviço fim-a-fim. Diante deste cenário é proposta nesse trabalho a definição, implementação e validação de uma solução para monitoramento de transmissão de mídia que permite ser aplicada em arquiteturas de redes heterogêneas. Essas redes possuem a característica de integrar diversas tecnologias de redes de comunicação de dados e de telecomunicações, envolvendo redes modernas e antigas, padronizadas e proprietárias.

Este trabalho apresenta um sistema de monitoramento para transmissão de TV Digital em ambientes heterogêneos convergentes, isto é, redes que utilizam tecnologias e meios de transmissão distintos para transmissão de vários tipos de fluxos, e com foco na aplicação TV Digital. Para isso, são discutidos aspectos fundamentais para o monitoramento de fluxo de TV Digital neste tipo de rede e é feita uma análise da comunicação entre os subsistemas do ambiente. O sistema de monitoramento possui uma arquitetura definida que se baseia no protocolo RTP Real-time Transport Protocol, para suportar a transmissão de mídias, como áudio e vídeo, em redes heterogêneas. A fim de validar esta arquitetura foi implementado um protótipo, como prova de conceito, que obtêm dados através da base de informações de gerência (MIB) RTP. Os resultados gerados pelo protótipo consolidam informações relativas à variação de atraso em uma interface web de gerenciamento através de monitores distribuídos pela rede.

Palavras-chave: Gerenciamento de Redes, Redes Convergentes, Monitoramento de fluxo de mídia, TV Digital, Qualidade de Serviço 


\section{Abstract}

The great evolution in the telecommunication systems related to the transmission of multimidia contents in the data communication networks and TV transmission, demands management solutions in which regards quality of end-to-end services. Taking this scenario into consideration, it is proposed in this work the definition and implementation of a solution to monitor media transmition that can be applied to heterogeneous network architectures. The feature of such networks is to integrate different data communication network technologies and telecommunication, involving legacy and modern networks, standarized and proprietary.

This work presents a monitoring system for digital TV transmission in heterogeneous converging environments, that is, networks that use different technologies and transmission means for the Digital TV application. Therefore, key aspects for monitoring the digital TV flow in this kind of network are pointed out, as well as an analysis of the communication among the environment subsystems. The monitoring system has a defined architecture, based on the RTP Real-time Transport Protocol, to support the media transmission, such as audio and video, in heterogeneous networks. In order to validate this architecture, a prototype was implemented, as concept evidence, that obtains data from the management information base (MIB) RTP. The results generated by the prototype consolidate information related to the delay variation (jitter) in a management web interface through monitors distributed around the network.

Keywords: Network Management, Media Stream Monitoring, Digital TV, Quality of Service 


\section{Lista de Figuras}

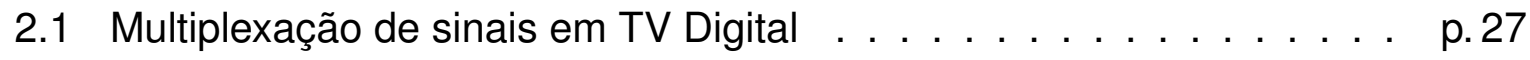

2.2 Topologia de rede proposta pelo projeto INSTINCT $\ldots \ldots \ldots \ldots$ p. 28

2.3 Comunicação entre subsistemas $\ldots \ldots \ldots \ldots \ldots \ldots \ldots$. . . . . . . . .

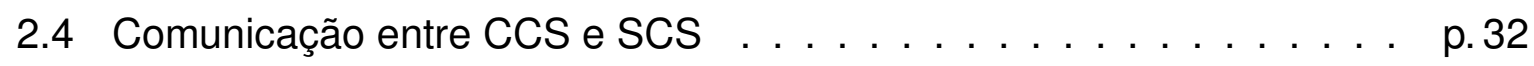

2.5 MPEG2 Transport Stream . . . . . . . . . . . . . . . . . p. 33

2.6 Comunicação entre SCS e Gateway . . . . . . . . . . . . . . p.35

2.7 Comunicação entre o Gateway e o terminal . . . . . . . . . . . . p. 36

2.8 Pilha de protocolos para transmissão de conteúdo multimídia . . . . . p.38

2.9 Diagrama do Transmissor RTP . . . . . . . . . . . . . . . . . p.39

2.10 Diagrama do Receptor RTP . . . . . . . . . . . . . . . . p. 40

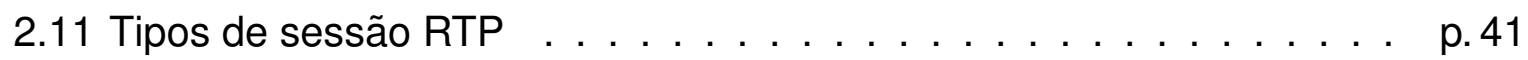

2.12 Estrutura do cabeçalho RTP . . . . . . . . . . . . . . . . . p. 42

2.13 Arquitetura do Modelo de Referência da OMG . . . . . . . . . p.53

2.14 Hierarquia da MIB RTP $\ldots \ldots \ldots \ldots \ldots \ldots \ldots$

2.15 Interface gráfica do Rtpmon . . . . . . . . . . . . . p. 60

2.16 Interface gráfica do Rtpmonitor . . . . . . . . . . . . p.61

3.1 Visão simplificada da arquitetura $\ldots \ldots \ldots \ldots \ldots \ldots$. . . . . . . 63

3.2 Arquitetura do sistema de gerenciamento em redes heterogêneas . . p.65

3.3 Arquitetura do Sistema de Monitoramento . . . . . . . . . . . p.67

3.4 Posicionamento dos Monitores RTP na rede . . . . . . . . . . p. 68

4.1 Distribuição dos Monitores RTP na topologia de rede simplificada . . p.71

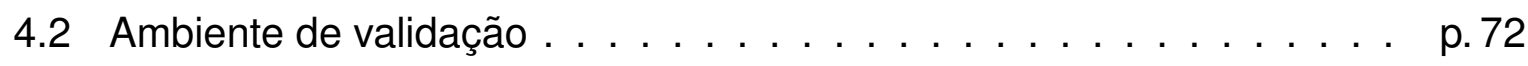


4.3 Interface web do Gerente com informações de variação de atraso . . p.76

4.4 Gráficos de variação de atraso no Monitor 1 . . . . . . . . . . . . . . . p. p7

4.5 Gráficos de variação de atraso no Monitor $2 \ldots$. . . . . . . . . . . . . p. 77

4.6 Gráficos de variação de atraso no Monitor 3 . . . . . . . . . . . . . . . p. 77 


\section{Lista de Tabelas}

2.1 Exemplos de tipos de payload type . . . . . . . . . . . . . . p. p3

2.2 Soluções de gerência mais comuns . . . . . . . . . . . . . . . . p.54

3.1 Matriz para cálculo da variação de atraso (jitter) $\ldots$. . . . . . . . . p. 69

4.1 Valores dos campos do protocolo RTP sem perturbação na rede . . . p.74

4.2 Valores dos campos do protocolo RTP com perturbação na rede . . . p. 75 


\title{
Lista de Abreviações e Siglas
}

\author{
AAC - Advanced Audio Coding \\ ATM - Assynchronous Transfer Mode \\ ATSC - Advanced Television Systems Committee \\ BSS - Broadcast Satellite service \\ CATV - Cable TV \\ CDMA - Code Division Multiple-Accesses \\ CIM - Common Information Model \\ CMIP - Common Management Information Protocol \\ CORBA - Common Object Request Broker Architecture \\ DASE - Digital Television Application Software Environment \\ Diffserv - Differentiated Services \\ DTT - Digital Terrestrial TV \\ DTTB - Digital Terrestrial Digital broadcasting \\ DVB - Digital Video Broadcasting \\ DVB-C - DVB - Cable
}

DVB-CBMS - DVB - Convergence of Broadcast and Mobile Services

DVB-H - DVB - handheld

DVB-MHP - DVB - Multimedia Home Platform

DVB-T - DVB - terrestrial

GPRS - General Packet Radio Service 
GSM - Global System for Mobile Communications

HD-MAC - High Definition Multiplexed Analog Components

HDTV - High Definition TV

HTTP - Hypertext Transfer Protocol

HTTPS - Secure HTTP

IETF - Internet Enginnering Task Force

Intserv - Integrated Services

IP - Internet Protocol

MAC - Multiplexed Analog Components

MAN - Metropolitan Area Network

MHP - Multimedia Home Platform

MIB - Management Information Base

MPEG - Moving Picture Experts Group

MPLS - Multiprotocol Label Switching

PID - Packet ID

PES - Packetized Elementary Stream

PMT - Program Map Tabl

QoS - Quality of Service

RSVP - Resource Reservation Protocol

RTP - Realtime Transfer Protocol

SFN - Single Frequency Network

SIG - Service Level Agreement

SLA - Service Level Agreement

SLM - Service Level Management 
SNMP - Simple Network Management Protocol

TCP - Transmission Control Protocol

TMN - Telecommunications Management Network

ToS - Type of Service (Tipo de Serviço)

TS - Transport Stream

UDP - User Datagram Protocol

UMTS - Universal Mobile Telecommunications System

WAN - Wide Area Network

WBEM - Web-Based Enterprise Management

WMI - Windows Management Instrumentation

XML - Extensible Markup Language 


\section{Sumário}

1 Introdução p. 19

1.1 Motivação . . . . . . . . . . . . . . . . . . . . p. 19

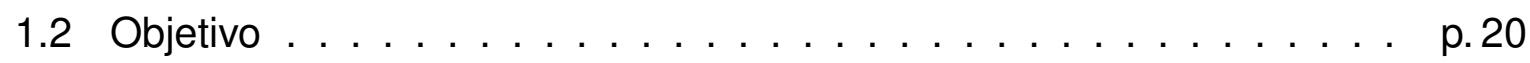

1.3 Estrutura e conteúdo da dissertação . . . . . . . . . . . . . . . p. 21

2 TV Digital e Gerenciamento de Redes p.22

2.1 TV Digital . . . . . . . . . . . . . . . . . p. 22

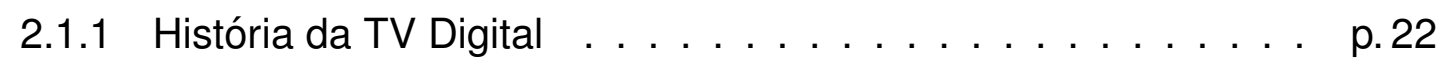

2.1 .2 DVB . . . . . . . . . . . . . . . . . . p. 24

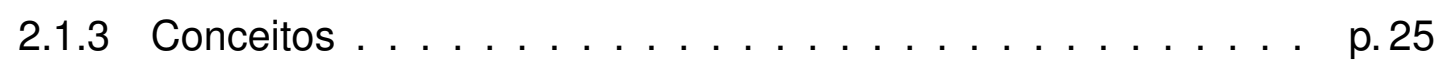

2.1.4 Apresentação da topologia de rede do sistema . . . . . . . . p. 27

2.1.5 Comunicação entre os subsistemas . . . . . . . . . . . . p. 31

2.2 RTP - Real-time Transport Protocol . . . . . . . . . . . . . . . . p. 35

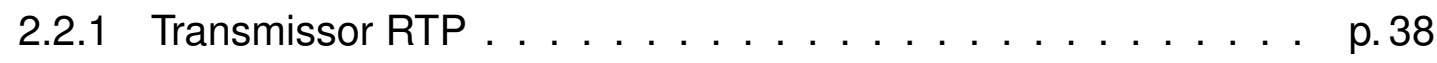

2.2 .2 Receptor RTP . . . . . . . . . . . . . . . . . . . . . . p.39

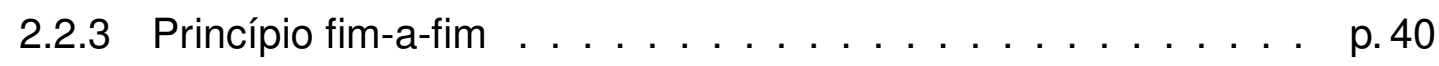

2.2 .4 Sessão RTP . . . . . . . . . . . . . . . . . . . . . p. 41

2.2.5 A estrutura do cabeçalho RTP . . . . . . . . . . . p. 42

2.3 Soluções de Gerenciamento de Redes . . . . . . . . . . . . . . . . . p. 45

2.3.1 Arquiteturas de gerenciamento de redes . . . . . . . . . . p. 46

2.3.2 Soluções de gerenciamento por domínio . . . . . . . . p. 53

2.4 RTP Management Information Base (MIB) . . . . . . . . . . . . . p.54

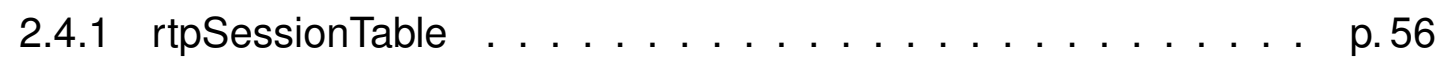

2.4 .2 rtpSenderTable . . . . . . . . . . . . . . . . . p. 57

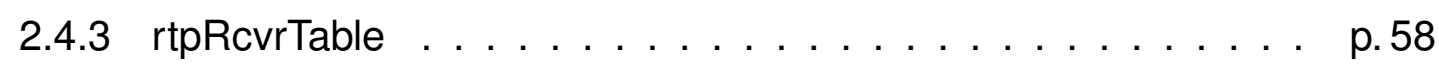

2.5 Trabalhos Relacionados . . . . . . . . . . . . . . . . p.59

2.5 .1 Rtpmon . . . . . . . . . . . . . p. 59

2.5 .2 RTPMonitor . . . . . . . . . . . . p. 60 
3 Sistema de monitoramento de transmissão de TV Digital p.62

3.1 Sistema de Controle de QoS . . . . . . . . . . . . . . . . . . . . p.62

3.2 Objetivos do Sistema de Monitoramento . . . . . . . . . . . . . . p. 63

3.3 Apresentação do sistema de gerenciamento da rede . . . . . . . . . . . p. 64

3.4 Descrição e funcionalidade dos componentes . . . . . . . . . . . . . p. 66

3.4.1 Subsistema de Gerenciamento de Domínio - SGD . . . . . . . p. 66

3.4.2 HQoSB - Heterogeneous QoS Broker . . . . . . . . . . . . . . p. 67

3.4 .3 Monitor RTP . . . . . . . . . . . . . . . . . . . p. 68

3.4.4 Base de dados de engenharia de tráfego . . . . . . . . . . p.70

4 Validação da especificação e implementação $\quad$ p.71

4.1 Ambiente de validação . . . . . . . . . . . . . . . . . . . . . . p.71

4.2 Resultados da validação . . . . . . . . . . . . . . . . . . . p.73

5 Conclusões $\quad$ p. 78

5.1 Contribuições . . . . . . . . . . . . . . . . . . . . . . . . . p. 79

5.2 Trabalhos Futuros . . . . . . . . . . . . . . . p. 80

$\begin{array}{ll}\text { Referências Bibliográficas } & \text { p. } 82\end{array}$ 


\section{Introdução}

Atualmente, muitos países europeus estão iniciando a utilização de transmissão de TV digital por difusão (DTT - Digital Terrestrial TV). Com a inserção comercial de tecnologias móveis $3 G$ e a utilização de DTT, é possível atingir um estado de alto grau de mobilidade e interatividade, em que novos serviços e aplicações poderão ser criados (SHULZYCKI, 2003).

Uma rede que implementa serviços através de TV Digital por difusão com mobilidade e interatividade tem um alto grau de complexidade. Isto, porque é um ambiente heterogêneo, que envolve redes de TV Digital de difusão, WANs e MANs IP e redes celulares em um ambiente multi-domínio e com vários participantes no modelo de negócio. Além disso, tem a intenção de oferecer serviços multimídia através de redes de comunicação de dados, o que torna necessária a utilização de mecanismos de controle e monitoração de QoS (Qualidade de Serviço);

\subsection{Motivação}

Este trabalho foi elaborado como parte de uma solução para gerenciamento de redes heterogêneas convergentes, isto é, redes que utilizam diversas tecnologias e meios de transmissão, como ATM, DVB-T, IP, GSM entre outras, em conjunto, para uma mesma aplicação nem sempre interconectadas com tecnologia de comunicação IP. Esse tipo de rede faz parte da arquitetura proposta pelo projeto INSTINCT (IP-based Networks, Services and Terminals for Converging Systems) (GABOS et al., 2006).

O INSTINCT foi um projeto europeu criado com o objetivo de implementar o recém criado padrão DVB-CBMS de transmissão de TV Digital por difusão para dispositivos móveis. Este projeto visava criar uma plataforma de serviços convergentes com 
mobilidade utilizando os padrões Digital Video Broadcasting - Terrestrial (DVB-T), Digital Video Broadcasting - Handheld (DVB-H) e Digital Video Broadcasting - Multimedia Home Platform (DVB-MHP) em conjunto com conceitos de comunicação sem fio, como General Packet Radio Service (GPRS) e Universal Mobile Telecommunications System (UMTS), além de redes terrestres de transmissão DVB por difusão.

Existe uma vasta quantidade de serviços que podem ser oferecidos combinando DVB e rede celular. Alguns dos principais serviços que podem ser disponibilizados são os serviços interativos audiovisuais, que pemitem o usuário assistir a conteúdos digitais e interagir com outros provedores de serviços de informações, responsáveis por fonecer notícias, informações de lazer, guias de viagem, informações de tráfego em cidades etc.

\subsection{Objetivo}

O objetivo deste trabalho é propor um sistema de monitoramento para redes e sistemas em um ambiente convergente e heterogêneo para TV Digital interativa móvel. Entende-se por ambiente heterogêneo um conjunto de redes que utilizam diferentes padrões e protocolos de comunicação, que convergem para dar suporte a transmissão de fluxos de TV Digital. O sistema de monitoramento propõe um ambiente capaz de obter informações de qualidade de serviço de uma transmissão de TV Digital. Ele permite analisar o estado das redes que transportam fluxos de vídeo, enviando relatórios à arquitetura de controle de QoS.

Uma arquitetura com condições de analisar parâmetros de qualidade de serviço envolve elementos capazes de monitorar a transmissão de um fluxo de vídeo em um ambiente heterogêneo e convergente, manter uma base de dados de engenharia de tráfego, que poderá ser utilizada por outros sistemas, como os de controle de QoS, fornecer informações para sistemas de SLM (Service Level Management), além de informações para usuários da rede, como provedores de conteúdo e serviços multimídia para TV Digital além de gerar alarmes quando algum nível pré-estabelecido de qualidade de serviço for alcançado. 


\subsection{Estrutura e conteúdo da dissertação}

Com a finalidade de dar apoio e suporte ao desenvolvimento do trabalho aqui proposto, é necessário um estudo dos conceitos envolvidos em TV Digital e em Gerenciamento de Redes de Computadores. Estes conceitos principais são apresentados no Capítulo 2, que inicialmente aborda conceitos de TV Digital e a apresentação da topologia de rede heterogênea do sistema de distribuição de fluxos de mídia. Em seguida, neste mesmo capítulo é apresentado o protocolo RTP, utilizado para transportar e fornecer informações do nível de Qualidade de Serviço das mídias (áudio e vídeo). Por fim, o capítulo introduz as principais arquiteturas de Gerência de Redes e a base de informações de gerência RTP (MIB-RTP).

No capítulo 3, é apresentado o sistema de Gerência de Redes Heterogêneas, detaIhando os componentes deste sistema, troca de mensagens entre eles e como estas informações são guardadas e acessadas por outras entidades da rede.

O Capítulo 4, por sua vez, descreve o processo de implementação e validação do Monitor RTP, principal componente do Sistema de Monitoramento de TV Digital, detaIhando os resultados obtidos pelo gerente SNMP (Simple Network Management Protocol) a partir de informações obtidas pelo agente Monitor RTP.

Por fim, o Capítulo 5 conclui este trabalho fazendo uma análise dos objetivos atingidos e consolidando as principais informações apresentadas. Este capítulo descreve as contribuições relevantes, fruto do desenvolvimento do trabalho, bem como os trabaIhos futuros, abordando de que maneira esta pesquisa pode evoluir. 


\section{TV Digital e Gerenciamento de Redes}

Este capítulo tem por objetivo apresentar conceitos de TV Digital e de Gerenciamento de Redes de computadores. Em TV Digital serão descritos os principais tipos de codificação de vídeo e o protocolo de transmissão de vídeo RTP. Mais adiante são descritas as principais arquiteturas de gerenciamento de redes e a Base de Informações de gerenciamento (MIB) RTP.

\subsection{TV Digital}

A televisão foi, e é o principal meio de comunicação com a população no último século e atualidade, tendo como base a transmissão por difusão, isto é, o mesmo sinal de antena enviado por uma estação de televisão é recebido por milhares de residências. No Brasil, estima-se que $90 \%$ da população tenha acesso a pelo menos um canal aberto de televisão. Esta cobertura ainda não foi atingida por nenhum outro meio de comunicação e talvez esta conquista nunca seja realizada pelos outros métodos de acesso existentes hoje, nem mesmo a Internet.

\subsubsection{História da TV Digital}

A televisão digital teve seu início em 1970, quando a rede de TV pública do Japão NHK (Nippon Hoso Kyokai) patrocinou seus cientistas do NHK Science \& Technical Research Laboratories para desenvolver uma TV de alta definição (HDTV).

Os esforços estavam direcionados para a pesquisa de uma solução tecnológica capaz de dar ao telespectador as sensações mais próximas possíveis, tanto em imagem 
quanto em som, daquelas experimentadas por um espectador no cinema. Isso exigia não só maior nitidez da imagem e estabilidade na transmissão, mas também uma tela com dimensões proporcionais às das salas de projeção.

Para isso era necessário aumentar o número de linhas e colunas de resolução do receptor. Além disso, os técnicos japoneses perceberam que seria ainda mais difícil melhorar a qualidade da transmissão a partir da plataforma analógica. Além disso não existia tecnologia capaz de realizar a compressão necessária para a transmissão de informação no volume exigido pela alta definição a partir de um canal tradicional de $6 \mathrm{MHz}$. Este problema foi solucionado com as tecnologias de compressão e multiplexação.

Na década de 1980, um consórcio de empresas passou a transmitir o serviço Digital $\mathrm{Hi}$-Vision Broadcasting durante uma hora por dia. Este era o início do HDTV. Na Europa, os pesquisadores, patrocinados pela Comunidade Européia fixaram-se também no desenvolvimento de um padrão, e em 1986, chegaram a uma alternativa similar à japonesa, batizada de MAC ${ }^{1}$. Para a alta definição, foi criada a versão HD-MAC, com maior resolução (ANNEGARN et al., 1987).

O final da década de 1980 e o início dos anos 1990 foram marcados pela implementação da solução final que seria conhecida mundialmente pela sigla MP3, o formato mais usado para compressão de arquivos de música na Internet. Em 1994, juntava-se ao MPEG-1 o MPEG-2. Com grande poder de compressão, a segunda versão da tecnologia tornou-se o padrão oficial dos sistemas de Digital Video Disc (DVD) e da TV de alta definição (HDTV).

Em 28 de novembro de 1995, o Acats $^{2}$ recomendou que a agência do governo dos EUA sugerisse o ATSC como o padrão norte-americano de televisão Digital. Antes disso, foram detalhadas as partes que comporiam o sistema: codificação de áudio e vídeo, multiplexação de sinais, modulação para transmissão e demodulação de áudio e vídeo para a recepção. Esses sistemas serão descritos em mais detalhes adiante.

Em maio de 1999, todas as emissoras estabelecidas nos 10 maiores mercados regionais americanos e afiliadas às maiores redes ( $A B C, C B S$, Fox e NBC) estavam requisitando autorização para transmitir com sinal digital. Seis meses depois, a 1 de

\footnotetext{
${ }^{1}$ Multiplexed Analogue Components - padrão de transmissão de televisão, originalmente proposto para utilização num sistema Europeu de HDTV terrestre

${ }^{2}$ Advisory Committee on Advanced Television Service
} 
novembro, as afiliadas destas quatro redes nos 30 maiores mercados dos Estados Unidos, entraram na fila pelo canal digital. Para todas as demais estações comerciais, incluindo as independentes, a FCC marcou o prazo final para 1 de maio de 2002 para o início das transmissões. As emissoras não-comerciais iriam começar a transição até 1 de maio de 2003.

Concebido com diversas semelhanças em relação à tecnologia européia DVB, o padrão japonês tem um diferencial importante: sua plataforma suporta múltiplas aplicações. Um canal de $6 \mathrm{MHz}$ foi projetado para suportar até 13 serviços ou emissoras diferentes. Em dezembro de 2000, houve a substituição pelo padrão totalmente digital ISDB. O país lançou comercialmente os serviços de televisao digital terrestre a partir de 2003.

\subsubsection{DVB}

O padrão DVB (Digital Video Broadcasting é conhecido como o padrão europeu de TV Digital. Ele é mantido pelo DVB Project, um consórcio com mais de 250 membros e detém um mercado atua de mais de 270 milhões de receptores pelo mundo. O DVB é um padrão que utiliza os mecanismos de compressão e transmissão do MPEG-2.

O DVB oferece conteúdo audiovisual em três configurações de qualidade de imagem: HDTV (High Definition Television), EDTV (Enhanced Definition Television) e SDTV (Standard Definition Television). Nas duas últimas configurações, é possível a transmissão simultânea de mais de um programa por canal, permitindo que até 4 programas sejam transmitidos simultaneamente.

O padrão DVB é designado de acordo com o serviço ao qual está vinculado:

- DVB-T - Transmissões Terrestres (TV aberta em VHF ou UHF convencional);

- DVB-C - Serviço de TV por Cabo;

- DVB-S - Serviço de TV por Satélite;

- DVB-H - Transmissão para dispositivos móveis;

- DVB-MHP - Padrão de middleware Multimedia Home Plataform. 
O sistema DVB-H é baseado no padrão DVB-T e o principal objetivo é a recepção de TV Digital em dispositivos móveis. A principal diferença neste padrão está na adição de time slicing e FEC (forward error correction) na camada de enlace. O time slicing reduz o consumo de bateria dos dispositivos em até $95 \%$ e também ajuda na transição de antenas quando o usuário deixa uma área de serviço e entra em uma nova célula. O uso do time slicing é mandatório no DVB-H. O FEC para encapsulamento de dados (MPE-FEC - Multiprotocol Encapsulated Forward Error Correction) melhora a relação sinal-ruído na transmissão aérea mas é opcional no DVB-H (FARIA et al., 2006).

\subsubsection{Conceitos}

O padrão MPEG tem como principal função combinar um ou mais fluxos de áudio e vídeo em um fluxo único de dados. O MPEG define a sintaxe dos fluxos de dados e controlar a sincronização e temporização do áudio e vídeo de uma aplicação. Um fluxo MPEG é constituído de uma camada de sistema e uma camada de compressão. A camada de compressão contêm os dados codificados de áudio e vídeo, enquanto a camada de sistema controla a demultiplexação(MITCHELL et al., 2002).

\section{Codificação de áudio e vídeo}

As especificações MPEG definem as padrões de codificação de áudio e vídeo a serem utilizados em sistemas de TV Digital. O MPEG-2 define também os meios pelos quais o Fluxo de transporte deve ser entregue para o usuário final.

O MPEG2 pode ser utilizado em várias aplicações, como TV por difusão, armazenamento digital de mídia, TV de alta definição (HDTV), e comunicação. Algumas das aplicações do padrão MPEG2 são: Serviço de difusão por satélite (BSS), TV à cabo (CATV), Difusão digital terrestre - Digital Terrestrial broadcasting (DTTB) dentre outras (MITCHELL et al., 2002).

O padrão MPEG2 evoluiu do MPEG1, que tinha como objetivo trabalhar com mídias de armazenamento com baixas taxas de erro. O MPEG2 trouxe resposta a alguns requisitos da época, tais como, funcionar também com redes ATM e lidar com vários programas simultâneamente sem necessitar de um relógio central sincronizado. $O$ sistema MPEG2 resolveu estes problemas definindo dois tipos de fluxo de dados: Os 
fluxos de programas - program streams (PS) e os fluxos de transporte - transport streams (TS). Esses em conjunto utilizam o mesmo fluxo básico empacotado - packetized elementary stream (PES).

Cada PES contém exatamente um fluxo básico de áudio ou vídeo. Os PES apresentam cabeçalhos que contêm informações de sincronismo, criptografia opcional, prioridade de pacotes, e numeração para sequencialização de pacotes. Como estas funcionalidades são oferecidas no PES, a troca tanto de PS como de TS mantêm suas características.

Pacotes PS tendem a ter tamanhos variáveis, tipicamente apresentando valores entre $1 \mathrm{k}$ e $2 \mathrm{k}$ bytes, mas podem chegar a até 64 kbytes. O PS carrega um único programa que consiste de múltiplos fluxos básicos de áudio e vídeo com uma sincronização comum, o relógio de referência do sistema - system clock reference (SCR). O fluxo de transporte pode suportar tanto um quanto múltiplos programas. Esses não necessitam compartilhar o mesmo sincronismo, mas devem ter rélogios de referência de programa - program clock reference PCR diferentes. O fluxo de transporte é independente do meio de transmissão que pode ser feita em ambientes com pequenas taxas de erro. Cada pacote tem exatamente 188 kbytes, cujo tamanho foi escolhido para facilitar o mecanismo de correção de erro - forward error correction a detectar erros.

A sincronização de fluxos básicos de áudio e vídeo é feita com a utilização de uma marca temporal presentation time stamps (PST) que informam quando o vídeo e áudio decodificados devem ser apresentados. Estes elementos de áudio, vídeo e dados que formam um programa são chamados de fluxos básicos - elementary streams (ES). Cada fluxo básico apresenta um identificador único dentro do fluxo de transporte (TS), chamado de identificador de programa - program identifier PID. Deste modo, programas são na verdade uma coleção de PIDs que são reproduzidos de modo sincronizado para o usuário final. A coleção de PIDs que forma um programa é indicada em uma grade de programação - program map table PMT, que na verdade é uma tabela que lista todos os PIDs de um determinado programa, sendo que cada PMT de cada programa possui um descritor do mesmo e um PID único que o identifica (MITCHELL et al., 2002). 


\section{Multiplexação}

Multiplexação é uma técnica empregada para permitir que várias fontes de informação compartilhem um mesmo meio de transmissão. Esta capacidade de transmitir diferentes mídias simultaneamente utiliza atualmente a mesma técnica de outros padrões existentes, que já fazem uso do fluxo de tranporte MPEG2-Transport Stream (MPEG2TS) como meio de transporte (MITCHELL et al., 2002).

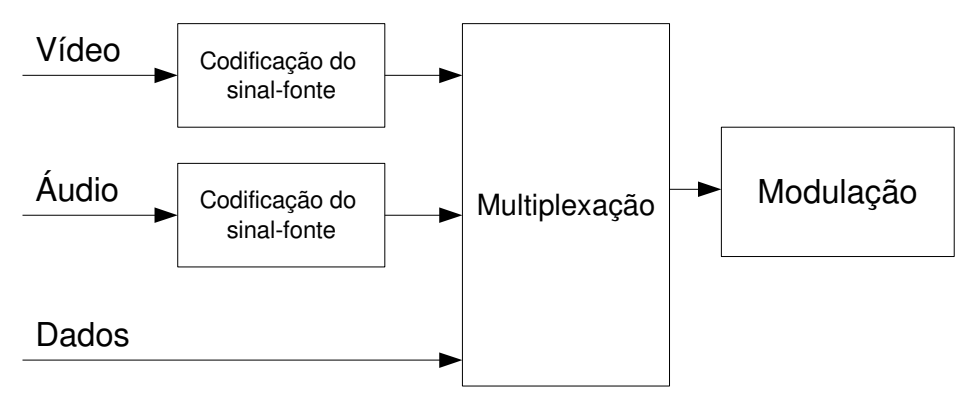

Figura 2.1: Multiplexação de sinais em TV Digital

Como mostrado na figura 2.1, os fluxos de áudio e vídeo são primeiramente codificados antes de serem multiplexados. Estes também devem ser decodificados após a demultiplexação do sinal no dispositivo final. No momento da demultiplexação, são utilizadas as tabelas MPEG2-Transport Stream (MPEG2-TS) para a identificação e decodificação dos programas.

O processo de codificação e decodificação de áudio e vídeo segue padrões que tem como objetivo atingir o máximo de compressão com uma qualidade de entrega aceitável. Essas codificações utilizam a técnica de compressão com perdas, que baseia-se em suprimir o que nossos ouvidos ou visão não percebem. Os sistemas atuais de TV digital utilizam os padrões de codificação de áudio e vídeo MPEG (MITCHELL et al., 2002).

\subsubsection{Apresentação da topologia de rede do sistema}

Esta sessão tem por objetivo apresentar a topologia da rede proposta pelo projeto INSTINCT desenvolvida para o provisionamento de TV digital para dispositivos móveis em um ambiente convergente (GABOS et al., 2006; BERG, 2004). Com base nesta topologia, é possível analisar os fluxos de mídia e definir os principais requisitos para o gerenciamento do transporte de vídeo numa rede heterogênea. 


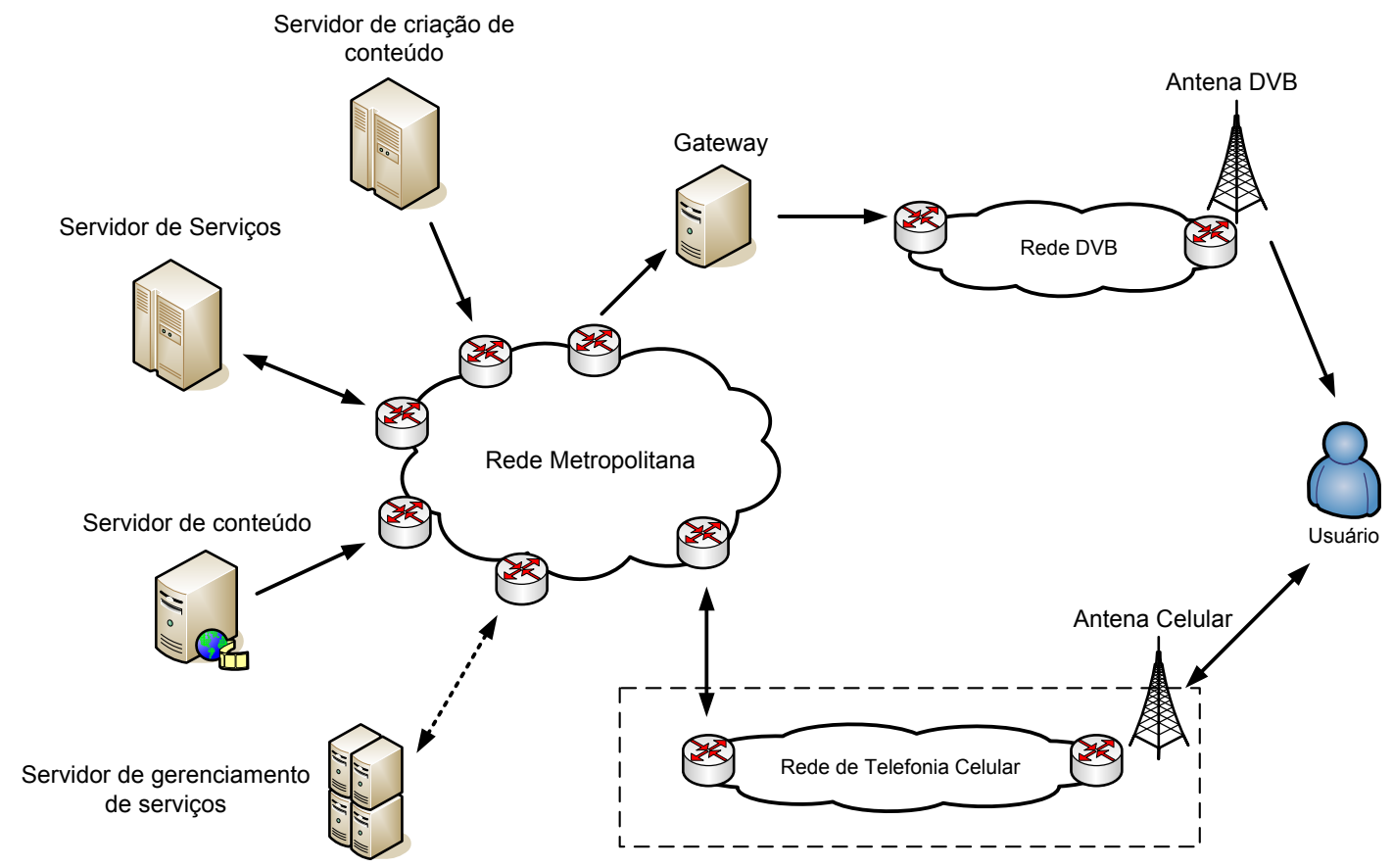

Figura 2.2: Topologia de rede proposta pelo projeto INSTINCT

Como demonstrado na figura 2.2 este sistema pode ser dividido em subsistemas e seus componentes serão descritos a seguir:

\section{Servidor de Criação de Conteúdo (SCC)}

Este servidor é responsável em codificar o conteúdo de áudio e vídeo obtidos do estúdio em DVB-T(Terrestrial Digital Video Broadcasting) e/ou DVB-H (Digital Video Broadcasting for Handhelds) (BRADEN et al., 1994). Além disso, o SCC é responsável pela criação da interface do usuário utilizando, por exemplo, um framework padrão como o MHP (Multimedia Home Platform) ou DASE (Digital TV Applications Software Environment) que serão enviados para o terminal do usuário através de fluxos básicos - Elementary Streams (EVAIN, 1998; MILENKOVIC, 1998). 


\section{Servidor de Serviços (SS)}

O servidor de serviços pode ser considerado o agregador de conteúdos do sistema. O SS recebe conteúdo de um ou mais servidores de criação de conteúdo e cria um único fluxo de tranporte (TS). Ele pode também receber requisições e respostas dos terminais através do canal de retorno, que pode ser GSM, UMTS ou outra tecnologia de transmissão de pacotes para terminais móveis. Este sistema também pode mudar a codificação do conteúdo recebido pelo estúdio para adaptá-lo tanto para terminais de baixa resolução (aparelhos celulares) quanto para terminais de alta resolução (setup-boxes HDTV) (BRADEN et al., 1994).

\section{Gateway (GW)}

O gateway é responsável por encapsular dados IP de diversas fontes em um fluxo de dados que será enviado para a rede DVB. As redes DVB na Europa utilizam em sua maioria tecnologia ATM para transmissão destes fluxos DVB até a antena (SCHAFER, 1996). O Gateway é também o responsável por transmitir dados, como por exemplo, uma página web através do fluxo DVB para o teminal.

\section{Antena}

As antenas tem como objetivo transmitir via interface aérea o fluxo de transporte gerado pelo Servidor de Serviços para o terminal móvel. A transmissão pode ser feita utilizando múltiplos canais (MFN - Multi-Frequency Network) como o sistema atual de televisão ou através de uma rede de frequência única (SFN - Single-Frequency Network), mesma tecnologia utilizada pelos aparelhos celulares.

\section{Terminal}

O dispositivo móvel que permite o usuário acessar os serviços e conteúdos transmitidos pela antena DVB ou pelo canal de retorno. As estações móveis são equipamentos utilizados pelos assinantes para ter acesso aos serviços da rede. Elas consistem em dois componentes principais: o equipamento móvel e o Subscriber Identity Module 
(SIM) caso o terminal tenha capacidade de utilizar o canal de retorno GSM. Somente com o SIM de um assinante a estação móvel tem privilégios para usar a rede. O SIM pode ser um chip instalado no equipamento móvel ou um cartão SIM.

\section{Servidor de Conteúdo (SC)}

O Servidor de Conteúdo dispõe de conteúdo previamente gerado e armazenado que pode ser transmitido para o terminal do usuário, podendo ser utilizado para serviços de vídeo sob demanda. A utilização do Servidor de Conteúdo dispensa a recodificação de conteúdo obtido do estúdio fazendo com que este possa ser transmitido diretamente para um Servidor de Serviços.

\section{Servidor de gerenciamento de serviços}

É responsável por coordenar o agendamento de serviços, gerenciar Service Level Agreements (SLA), manter requisitos de QoS de acordo com as regras de negócio estabelecidas entre os principais provedores de serviço. Este subsistema será descrito com mais detalhes adiante.

\section{Rede Celular}

A rede celular pode ser utilizada pelos dispositivos móveis como canal de retorno, existem tecnologias como GSM, UMTS, CDMA (Code Division Multiple-Accesses), entre outras para tal fim. Através do canal de retorno, os usuários poderão solicitar conteúdo, participar de programas interativos e até mesmo alimentar o sistema de gerenciamento de rede caso seu terminal possua uma base de informações de gerência. Além disso, pode também ser utilizado como canal de recepção de conteúdo (HEINE, 1999).

Em um sistema de TV interativa, existe a necessidade de um canal de retorno, onde os usuários podem fazer requisições de serviços ou mandar informações de qualidade de transmissão para as operadoras. No caso do dispositivo móvel, existe então, a necessidade de um canal de retorno sem fio. 
O padrão GSM Global System for Mobile Communications de telefonia celular é o mais popular do mundo. O serviço GSM é utilizado por mais de 2 bilhões de pessoas em 212 países. A mobilidade do GSM faz com que o roaming internacional seja muito comum entre operadores de telefonia celular, permitindo que usuários utilizem seus aparelhos em grande parte do mundo.

\subsubsection{Comunicação entre os subsistemas}

Esta seção tem como objetivo descrever a comunicação entre os componentes do sistema e apresentar os protocolos que devem ser utilizados para que a comunicação entre os subsistemas funcione eficientemente. A figura 2.3 mostra os subsistemas já apresentados considerando a comunicação de dados entre estes elementos. $O$ objetivo desta abordagem é esclarecer como estes subsistemas interagem e onde estão localizados. É importante notar que as conexões apresentadas são os fluxos de mídias da arquitetura apresentada e não os fluxos de sinalização (GABOS et al., 2006).

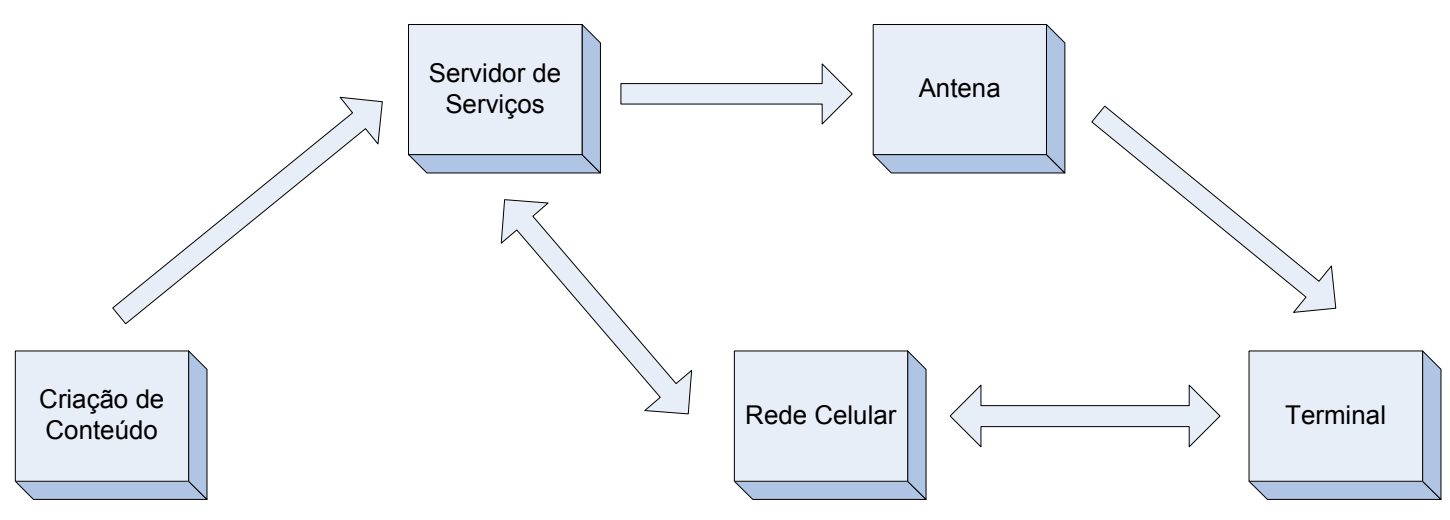

Figura 2.3: Comunicação entre subsistemas

Em seguida, esses elementos serão separados e serão apresentadas as possíveis comunicações entre eles. Também serão apresentados os protocolos utilizados para prover a comunicação entre estes subsistemas e a implementação de suas funções. 


\section{Comunicação entre o SCC e o SS}

O primeiro fluxo de mídias a ser considerado é entre o Servidor de Criação de Conteúdo (SCC) e o Servidor de Serviços (SS) como mostra a figura 2.4. O conteúdo gerado pelo SCC é codificado e distribuído através, por exemplo, de uma rede IP para o SS. Muitos serviços podem ser agregados e suas descrições são enviadas para o Servidor de Gerenciamento de Serviços. A partir desses dados, os SMSs podem então criar um guia de serviços eletrônicos Electronic Service Guide (ESG) para ser enviado para os terminais.

A figura 2.4 representa o conjunto de protocolos que são utilizados para implementar todas as funções necessárias para a transmissão de conteúdo entre o CCS e o SCS. Os protocolos utilizados e suas funcionalidades estão descritos abaixo.

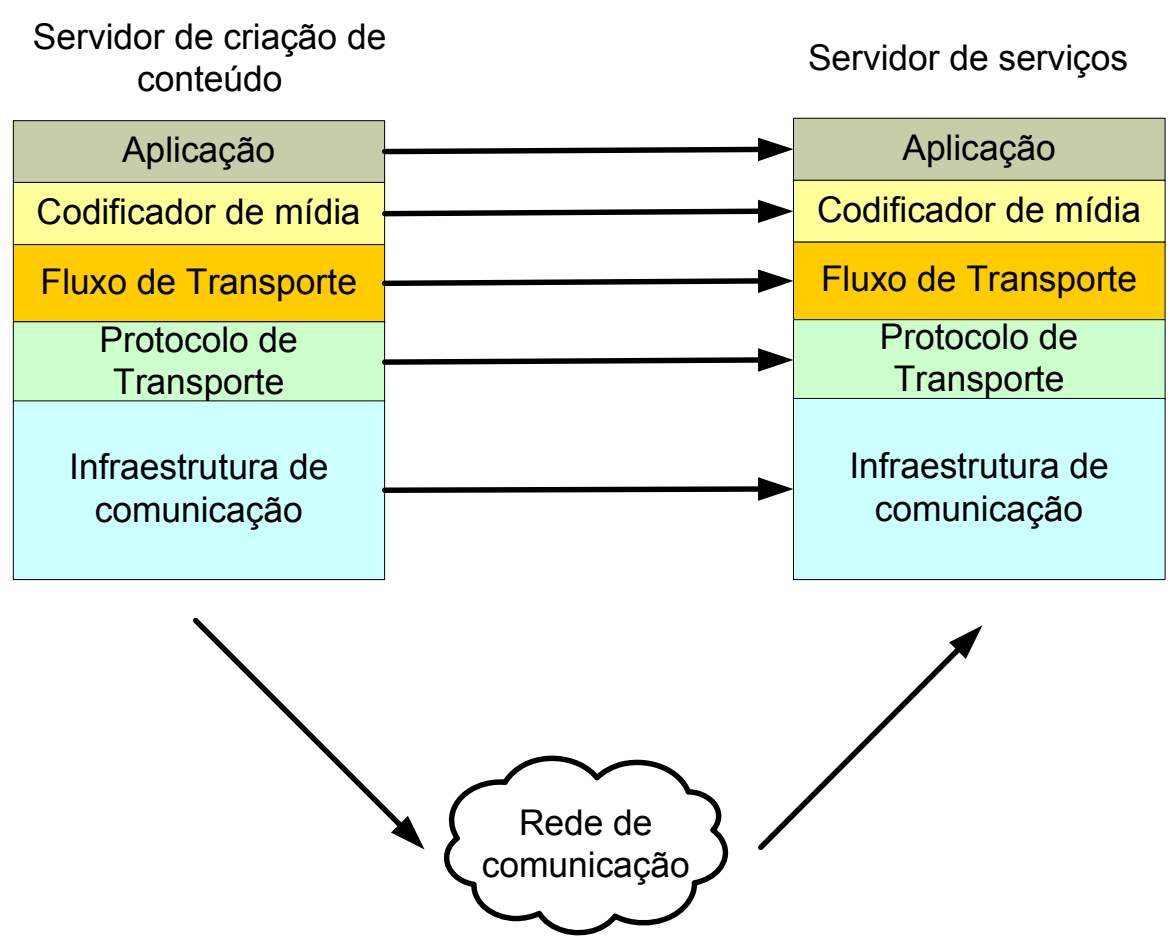

Figura 2.4: Comunicação entre CCS e SCS

1. Infraestrutura de comunicação: De acordo com o modelo de referência OSI (TANENBAUM, 1997), esta camada tem as funcionalidades da camada de enlace em conjunto com a camada de rede. A camada de enlace tem como objetivo transformar um canal de transmissão bruta de dados em uma linha que pareça livre dos erros de transmissão não detectados nas camadas superiores. Podemos citar como exemplo tecnologias de transmissão como o ATM, SDH e Ethernet. 
A camada de rede pode ser representada pelas camadas TCP/IP do modelo OSI (TANENBAUM, 1997). A presença destas duas camadas de protocolo, da arquitetura TCP/IP, significa que a comunicação entre o CCS e o SCS pode ser feita através de qualquer tipo de rede rede de comunicação. É importante ressaltar que a rede não precisa ser necessariamente TCP/IP. Para que esta comunicação seja feita, pode ser utilizado conexões diretas ou outro tipo de tecnologia de transmissão.

2. Protocolo de Transporte: Responsável pelo tranporte das mídias e dados. Neste trabalho, o protocolo responsável por esta tarefa será o RTP (Real Time Protocol) que será descrito em mais detalhes posteriormente.

3. Fluxo de Transporte: Esta é a camada que representa o DVB/ Transport Stream e consiste nos protocolos da tecnologia DVB. A figura 2.5 mostra em detalhe os campos dos cabeçalhos utilizados por esta camada abaixo relacionados.

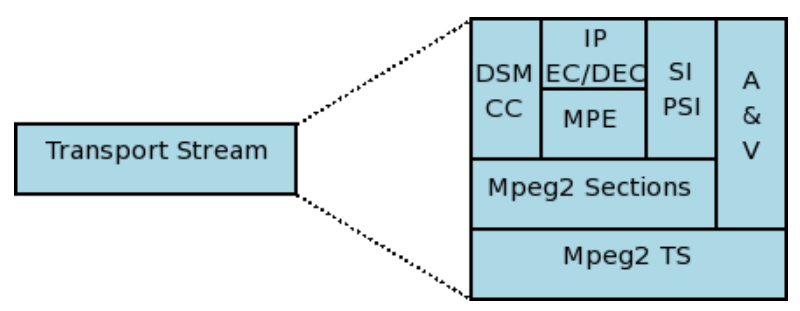

Figura 2.5: MPEG2 Transport Stream

- MPEG2 TS: O fluxo de tranporte MPEG2 Transport Stream combina vários fluxos básicos - Elementary Streams (ES) de áudio, vídeo e dados (HASKELL et al., 2002).

- A/V: Formado pelos fluxos básicos (ES) de áudio e vídeo.

- MPEG2 Sections: Encapsula dados que serão transportados em fluxos básicos específicos para o transporte de dados para o terminal.

- DSM-CC: O DSM-CC - Digital Storage Media Configuration and Control é um conjunto de ferramentas para fazer controle de fluxos. Pode ser utilizado para prover fuções de adiantar e atrasar fluxos de áudio e vídeo, além de transportar dados.

- SI/PSI: Os campos de informação de sistema - System Information (SI) ou informação de programas - Program System Information (PSI) carregam informações do conteúdo do fluxo DVB. Este campo pode ser utilizado para construir a grade eletrônica de programação -Electronic Program Guide (EPG) por exemplo. 
- MPE: Para o transporte de datagramas IP dentro de um fluxo de transporte (TS), utilizamos o campo MPE (The Multiple Protocol Encapsulation). Os dados do DVB-H são datagramas IP encapsulados no MPE.

- IP EC / DEC: IP Encapsulator/Decapsulator são datagramas IP ou de outro protocolo encapsulados no campo MPE.

4. Codificadores de mídia: Usados para codificar dados de áudio e vídeo, podemos citar como exemplo os formatos MPEG2, MPEG4, MP3, AAC etc.

5. Aplicação: O provedor de serviço deve fornecer meios para a execução e exibição do conteúdo, por exemplo, em uma partida de futebol, o usuário poderia selecionar diferentes câmeras. Para isso é necessária a utilização de um framework capaz de acessar a API (Application Program Interface) do terminal e prover interatividade entre o usuário e o serviço.

\section{Comunicação entre o SCS e o Gateway}

O SCS, após receber conteúdo de um ou mais CCS, gera o conteúdo que será transmitido para o usuário final. Este sistema deve implementar a camada de aplicação afim de preparar o conteúdo que será entregue para o terminal do usuário. É importante notar que a transmissão feita pelos SCSs ocorrem sempre através de um MPEG2 TS para a rede DVB.

A figura 2.6 mostra a pilha de protocolos utilizados para a transmissão dos fluxos de mídia entre o SCS e o GW. A a principal diferença entre esta comunicação e a citada anteriormente (CCS e SCS) é que na camada de aplicação temos agora o conceito de serviço. No sistema apresentado, serviço é a combinação de vários conteúdos em um novo TS.

\section{Comunicação entre o Gateway e o Terminal}

O Gateway se comunica com uma antena que recebe um único TS de um SCS e o transmitirá aos teminais dos usuários. O Gateway é capaz de gerar um único TS a partir de vários TSs recebidos de um ou mais SCSs. A figura 2.7 mostra a comunicaçao entre o Gateway e o terminal e seus protocolos utilizados. 


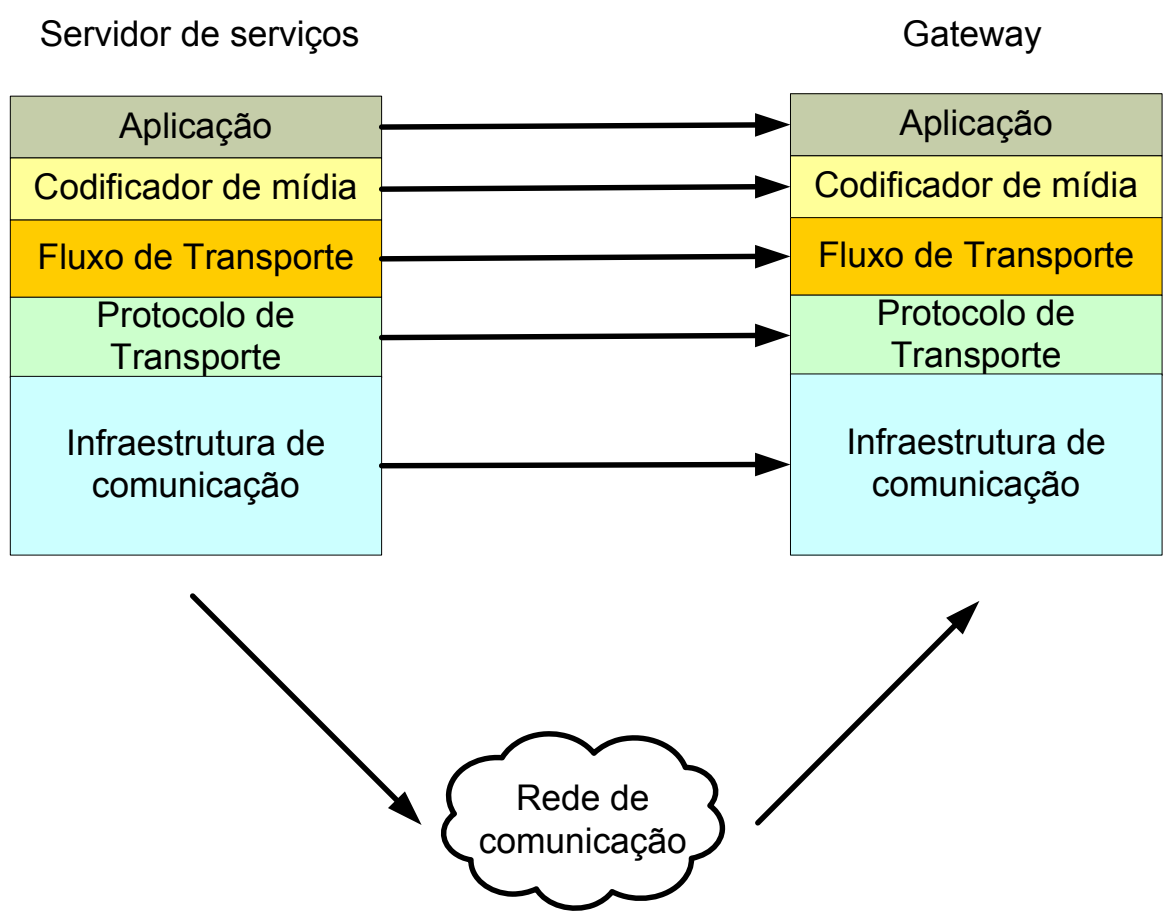

Figura 2.6: Comunicação entre SCS e Gateway

A infraestrutura de comunicação do DVB é representada pela camada física da transmissão por difusão. Pode-se citar o Single-Frequency Network (SFN) ou o MultiFrequency Network (MFN) como tipos de transmissão por antena para o terminal (WECK, 1996).

Através da topologia de rede apresentada em conjunto com a pilha de protocolos é possível definir os requisitos para a gerência do sistema proposto. Na próxima sessão será apresentado o protocolo RTP, que será o protocolo de transporte utilizado para a transmissão dos fluxos de mídia na rede. A partir de dados obtidos através do cabeçalho RTP poderemos alimentar a base do monitoramento de parâmetros de QoS do sistema. Em seguida serão apresentadas soluções de gerência de rede e a base de informação de gerenciamento (MIB) do protocolo RTP.

\subsection{RTP - Real-time Transport Protocol}

O RTP propõe um cabeçalho que suporta aplicações que transmitem dados em tempo real (como audio e vídeo), através de serviços unicast ou multicast. Ele foi desenvolvido pelo Audio-Video Transport Working Group do IETF e foi publicado pela primeira 


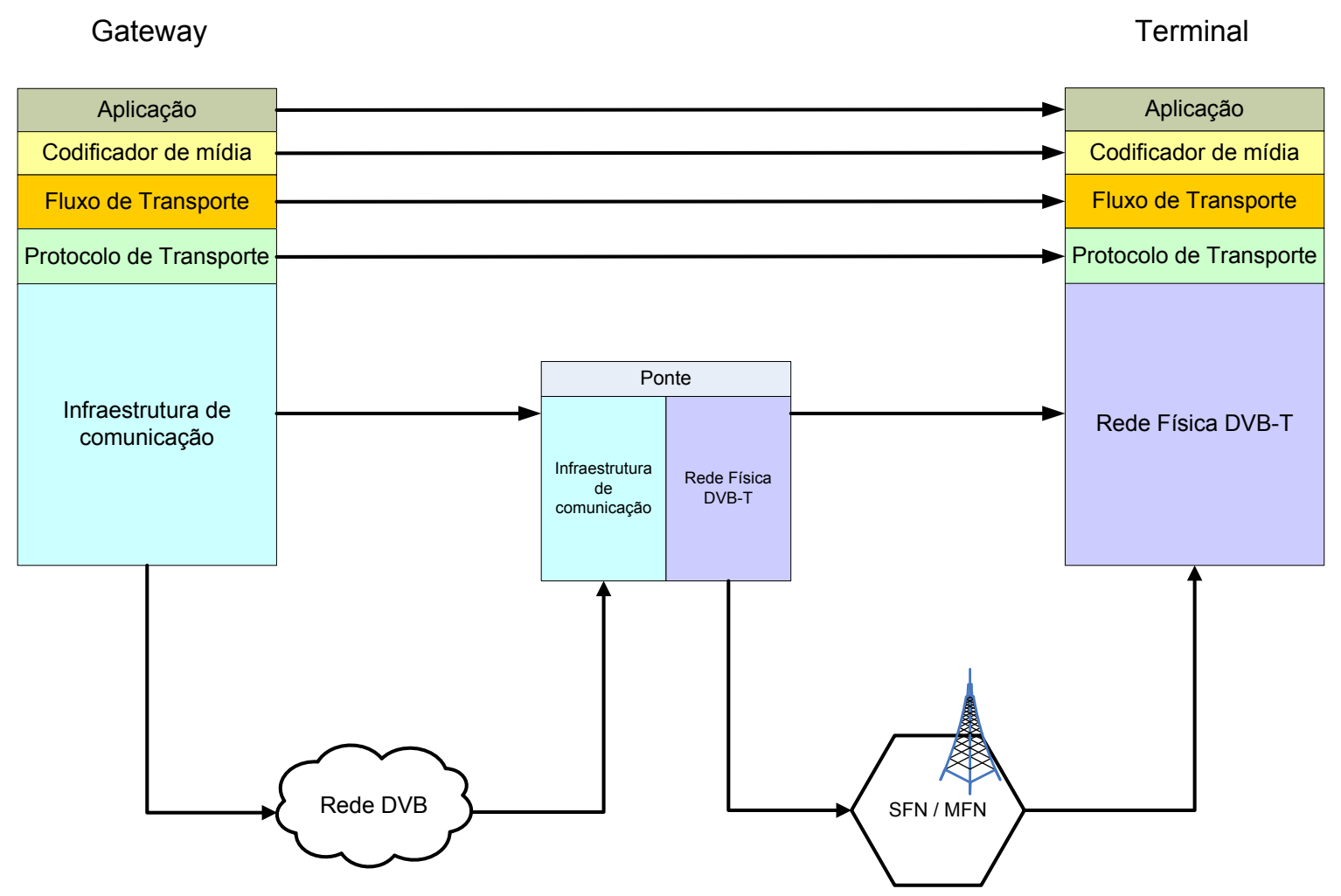

Figura 2.7: Comunicação entre o Gateway e o terminal

vez em 1996 através da RFC 1889 (SCHULZRINNE et al., 1996) a qual se tornou obsoleta em 2003, sendo substituída pela RFC 3550 (SCHULZRINNE et al., 2003). O principal objetivo do RTP é disponibilizar serviços para transporte de mídias de tempo real, como áudio e vídeo inicialmente em redes IP. Esses serviços incluem recuperação de sincronismo, detecção de erros, identificação do conteúdo e de sua origem, monitoração de qualidade de transmissão e sincronização de mídia. Inicialmente, o RTP foi desenvolvido para uso em conferências multicast mas se mostrou útil também para uma grande gama de aplicações: vídeo conferência $\mathrm{H} 323$, webcasting, e distribuição de TV; tanto em redes cabeadas quanto em redes sem fio (celular). O protocolo apresenta grande escalabilidade, podendo ser utilizado em sessões multicast com milhares de usuários. Além disso, suporta desde transmissões de vídeos de baixa taxa de bits (para aplicações de telefonia celular) até vídeos sem compressão de alta-definição (HDTV) com taxas de gigabits por segundo (PERKINS, 2003).

Aplicações de tempo real, como videoconferência e voz sobre IP, são muito mais sensíveis à qualidade de serviço da rede do que aplicações do tipo store-and-forward como correio eletrônico e transferência de arquivos. A qualidade de serviço se refere à inteligência da rede em oferecer a performance necessária para satisfazer algum tipo 
de aplicação. Em uma rede IP com serviços multimídia é importante que os dados continuem a ser transmitidos com confiabilidade na presença de aplicações de voz e vídeo e que a qualidade da transmissão multimídia não seja afetada por transferência de dados convencionais.

O transporte de pacotes RTP em redes ATM é feito utilizando-se a camada de adaptação AAL5 (ATM Adaptation Layer 5) como definido na recomendação ITU-T I.363.5. Esta camada de adaptação é utilizada para tranporte multiprotocolo, pois existe o encapsulamento e desencapsulamento dos dados, sendo o conteúdo transportado transparente para a rede ATM (FRASER et al., 1998).

Para descrever a qualidade de serviço em uma rede é necessário se preocupar com quatro parâmetros principais: atraso ou latência, tempo necessário para que o pacote atravesse a rede; jitter, variação de atraso entre pacotes, largura de banda, taxa de transmissão da rede, e perda de pacotes e porcentagem de pacotes que não chegam ao seu destino integros. Abaixo estão relacionados esses parâmetros mais detalhadamente:

- Atraso fim-a-fim: O atraso fim-a-fim é o tempo total que o pacote leva da sua origem ao seu destino. Uma videoconferência, por exemplo, não deve ter este valor superior a 125-150 ms. O tamanho médio de pacotes para transmissão de vídeo é geralmente grande (800-1500 bytes) enquanto pacotes contendo informações de áudio são menores (480 bytes ou menos). Isso significa que a latência média de um pacote contendo dados de áudio geralmente é menor que um pacote contendo vídeo, isto porque roteadores e switches geralmente priorizam pacotes menores quando existe congestionamento na rede.

- Jitter ou variação de atraso: Refere-se à variação de atrasos dos pacotes de um dado fluxo de dados e não deve ultrapassar 20-50 ms. Para exemplificar, se em uma sessão H.323 de $30 \mathrm{FPS}^{3}$ com atraso fim-a-fim de $115 \mathrm{~ms}$ um pacote sofrer um jitter de $145 \mathrm{~ms}$, este chegará ao seu destino com ordem alterada, podendo distorcer a imagem ou som da transmissão.

- Largura de banda: A largura de banda está relacionada à taxa de transmissão suportada pela rede. A transmissão de conteúdo multimídia requer uma largura de banda considerável dependendo da qualidade do vídeo e voz transmitidos.

- Perda de pacotes: O termo se refere à perda ou alteração do conteúdo do

${ }^{3}$ Frames per second - Quadros por segundo 
pacote de áudio e vídeo. Uma taxa de perda de pacotes de 1\% em uma transmissão multimídia causa perturbações na imagem e ruído na transmissão do áudio. Um valor acima de $2 \%$ pode comprometer significamente a transmissão, tornando-a incompreensível.

Em conjunto com o RTP, um sistema de transmissão de vídeo utiliza um conjunto de protocolos e padrões para inicialização de sessões, controle, compressão de mídias e transporte na rede. A figura 2.8 mostra como o RTP é a base para qualquer sistema de entrega de áudio e vídeo em tempo real. Ele fornece uma camada de transporte independente do protocolo de sinalização e aplicação.

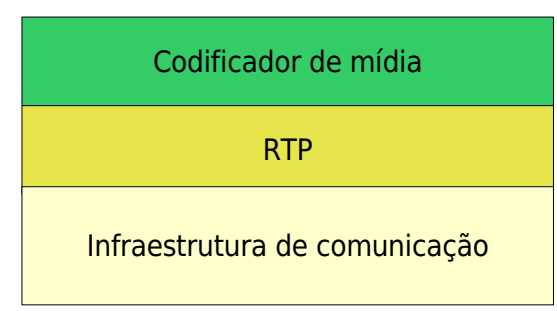

Figura 2.8: Pilha de protocolos para transmissão de conteúdo multimídia

\subsubsection{Transmissor RTP}

O transmissor é responsável por capturar e transformar dados de áudio e vídeo para serem enviados. Ele pode ser também utilizado para controle de erros e transmissão através de uma resposta do receptor. Um diagrama demonstrando o processo de transmissão é mostrado na figura 2.9 .

As mídias (áudio e vídeo) são capturadas e comprimidas em quadros. Estes quadros são então carregados em pacotes RTP prontos para serem enviados. Caso os quadros sejam grandes, eles são fragmentados em vários pacotes RTP ou então, se forem pequenos, vários desses podem ser colocados em um único pacote RTP (PERKINS, 2003). 


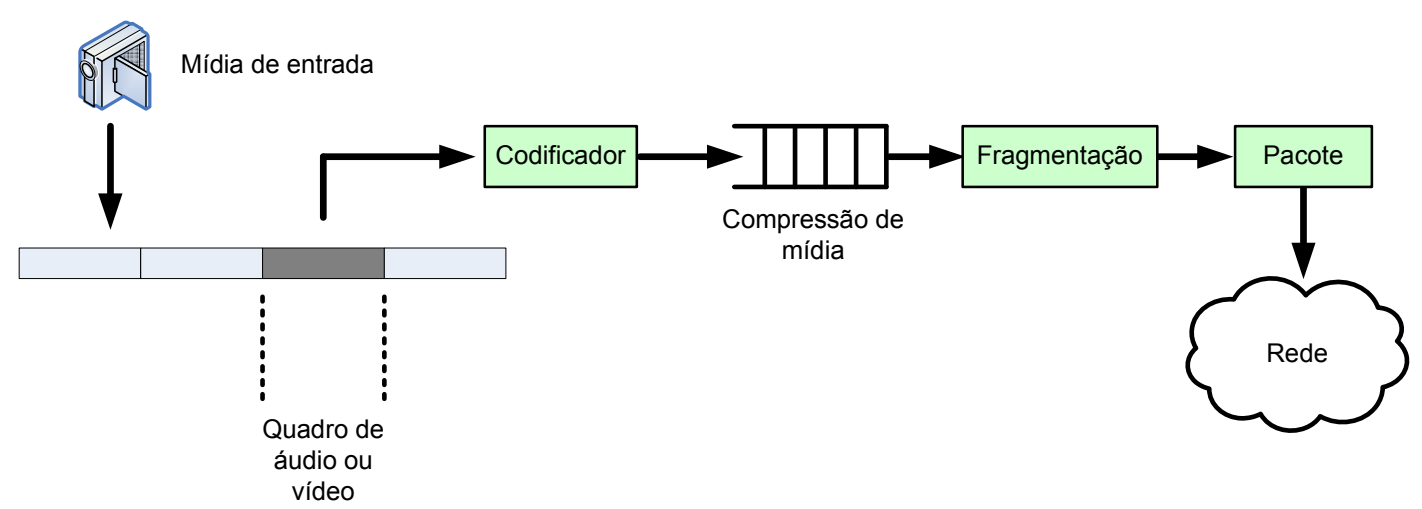

Figura 2.9: Diagrama do Transmissor RTP

\subsubsection{Receptor RTP}

O receptor é responsável por receber os pacotes RTP da rede, corrigir perdas, recuperar sincronismo, descomprimir a mídia, e apresentar o resultado para o usuário. $O$ receptor RTP também pode mandar informações quanto à transmissão de volta para o transmissor, dessa maneira é possível que este se adapte ao comportamento da rede. Um exemplo de diagrama representando o receptor RTP pode ser visto na figura 2.10.

O primeiro passo do processo de recepção é coletar os pacotes da rede, validá-los quanto a eventuais erros, e caso haja mais de um fluxo de mídia, inserí-los em uma fila específica. Os pacotes dessas filas são então inseridos em uma nova fila chamada memória de contenção - Playout Buffer. Os pacotes são então ordenados por timestamp eliminando qualquer tipo de reordenação ocorrida no transporte pela rede. Os pacotes são mantidos na memória de contenção até que um quadro completo seja recebido. Neste momento podem ser observadas diferenças nos relógios do transmissor e receptor. Este problema é corrigido pelo mecanismo correção de desvio - clock skew para evitar lacunas durante a execução da mídia e finalmente a mídia é assistida pelo usuário (PERKINS, 2003).

De acordo com a RFC 1889, os serviços oferecidos pelo RTP incluem (SCHULZRINNE et al., 1996):

- Identificação do conteúdo - descrição de que tipo de conteúdo está sendo trans- 


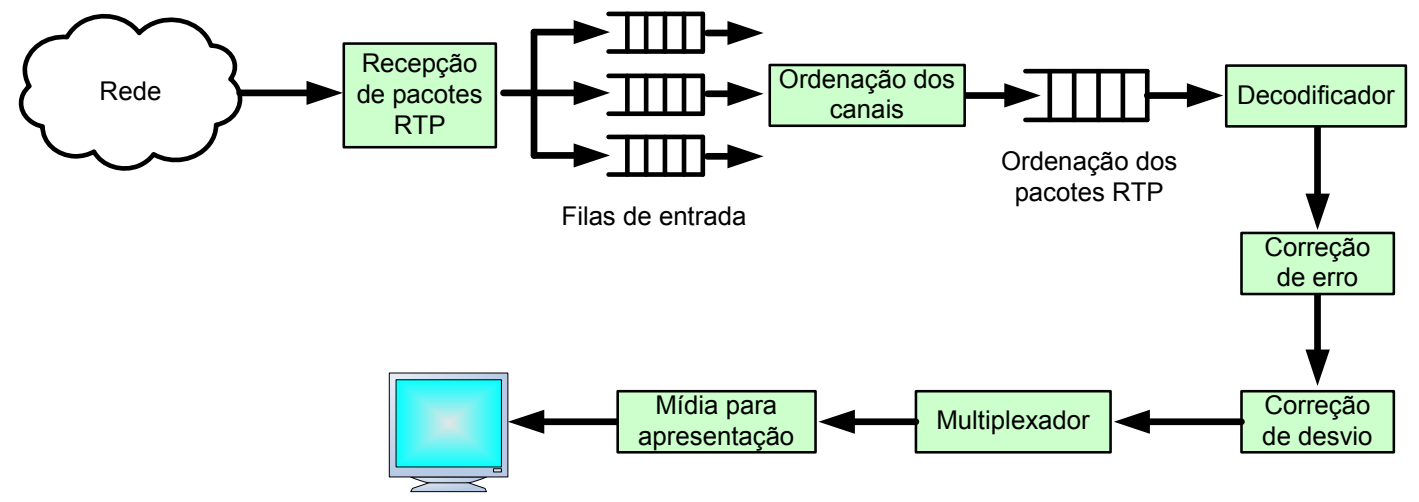

Figura 2.10: Diagrama do Receptor RTP

portado;

- Sequencialização;

- Time stamping - Registro do instante em que o pacote saiu da origem;

- Monitoração de entrega.

O protocolo por si só não possui mecanismos para garantir a entrega de seu conteúdo sincronizada. Ele também não possui nenhuma garantia de Qualidade de Serviço. Para isto devemos utilizar outros tipos de mecanismos que podem, através dos dados coletados pelo cabeçalho do RTP, recuperar erros e reordenar pacotes.

\subsubsection{Princípio fim-a-fim}

Uma das filosofias adotadas na criação do RTP foi o princípio de fim-a-fim. Essa é uma das possíveis maneiras que um sistema pode se comunicar através de uma rede. Existem os sistemas em que a responsabilidade de correção e detecção de erros está nos roteadores que estão no caminho de uma transmissão de dados. Em outros, a responsabilidade está nos pontos finais, garantindo a entrega de dados fim-a-fim mesmo que alguns roteadores do caminho não estejam transmitindo. Foi esta segunda abordagem que tornou possível o desenvolvimento da Internet, com o TCP e o RTP seguindo o princípio de comunicação fim-a-fim. A principal consequência do princípio fim-a-fim 
é que o controle do sistema tende a se manter nas camadas superiores do modelo de referência OSI. Um sistema que disponibiliza o meio de transmissão mas não se responsabiliza pela entrega de dados, pode ser mais simples e não necessariamente robusto, podendo assim discartar dados que não consegue entregar, pois os terminais podem recuperar tais dados. O princípio fim-a-fim implica no controle estar nos terminais e não na rede de transmissão.

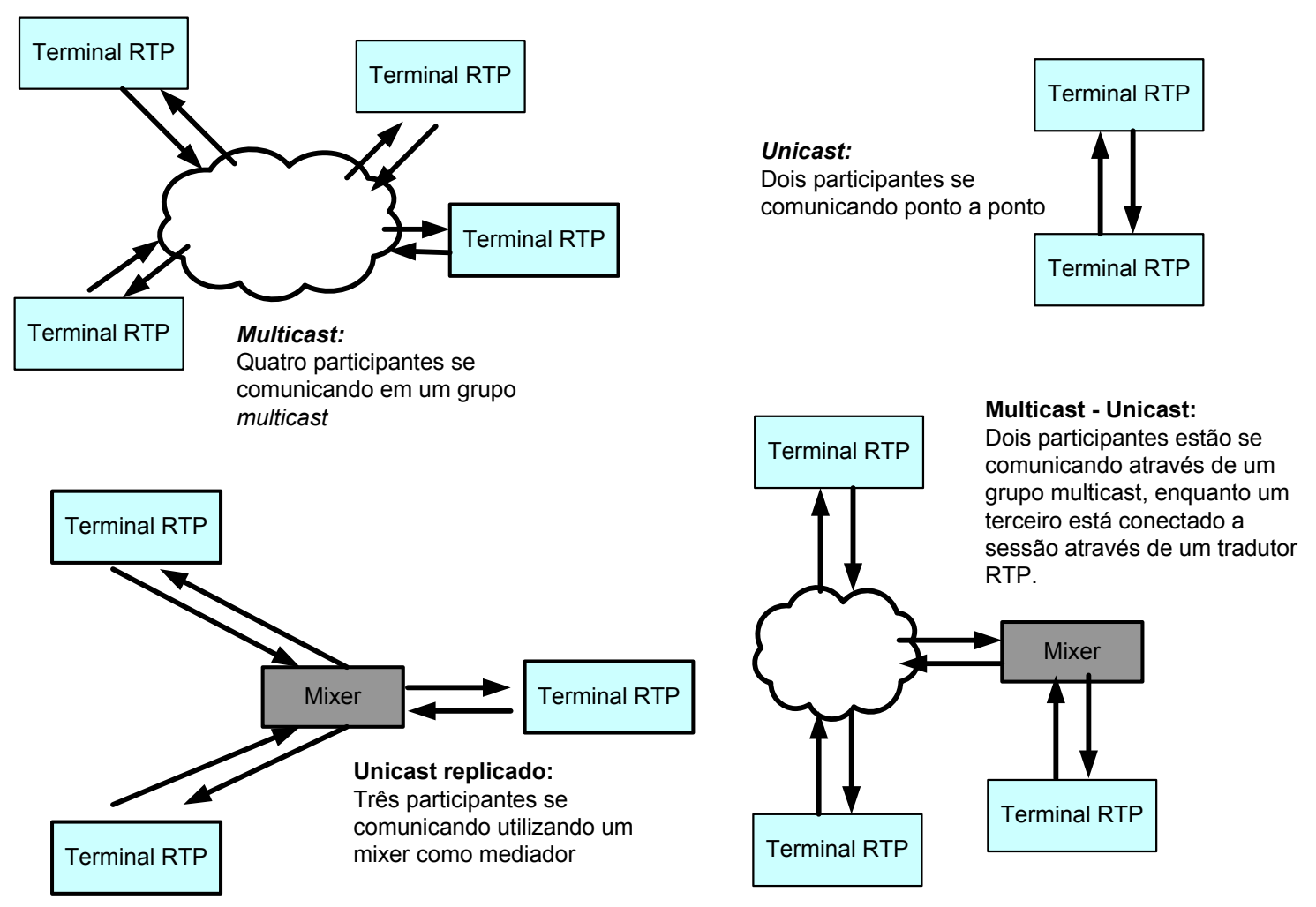

Figura 2.11: Tipos de sessão RTP

\subsubsection{Sessão RTP}

Uma sessão consiste em um grupo de participantes que estão se comunicando usando o protocolo de comunicação RTP. Um participante pode estar em múltiplas sessões, uma para dados de áudio e outra para dados de vídeo, por exemplo. Para cada participante, a sessão é identificada por um endereço de rede e um par de portas para as quais os dados devem ser enviados. As sessões RTP devem transportar um único tipo de mídia; em uma comunicação multimídia, cada uma delas deve ser carregada em uma sessão diferente. A sessão RTP pode ser unicast, feita diretamente entre dois participantes (ponto a ponto) ou através de um servidor que distribui a mídia. Alguns exemplos de topologia de sessões RTP são demonstrados na figura 2.11. 


\subsubsection{A estrutura do cabeçalho RTP}

O cabeçalho RTP possui 12 octetos. Os campos especificados pelo padrão são o tipo de payload, número de sequência, timestamp, e identificador de sessão. A figura 2.12 apresenta a estrutura de um pacote RTP; os campos serão explicados detalhadamente a seguir (SCHULZRINNE et al., 2003).

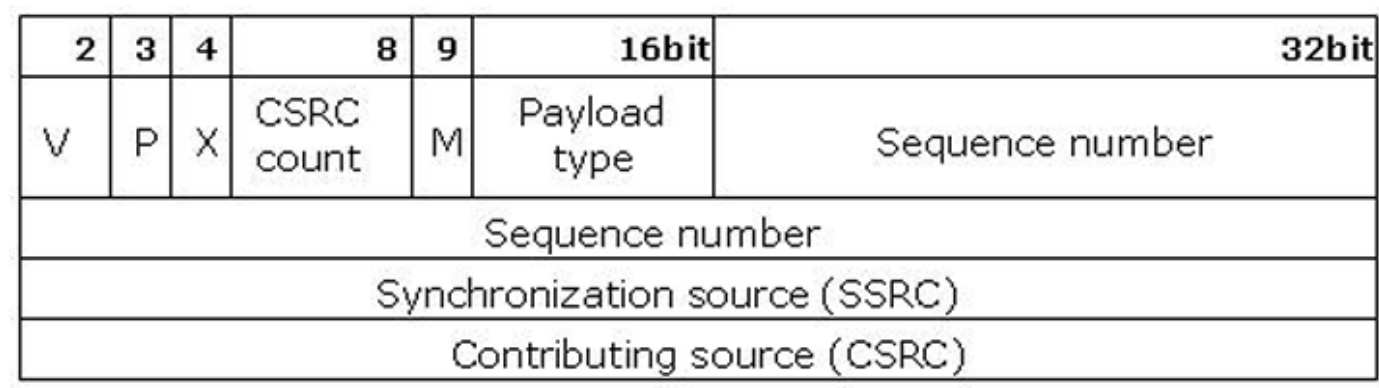

Figura 2.12: Estrutura do cabeçalho RTP

\section{Versão}

Cada pacote RTP contém um número de versão, indicado pelo campo V. O RTP atualmente está na versão 2. Não existem planos para implementação de uma nova versão. A única finalidade deste campo está relacionada à validação do pacote.

\section{Preenchimento (Padding)}

O bit de preenchimento - padding $\mathrm{P}$ é usado para indicar que o conteúdo contém preenchimento. Se um pacote RTP foi preenchido com padding, o bit é configurado para o valor 1 e o último octeto do payload possui o número de octetos de padding. Esta funcionalidade raramente é utilizada mas é necessária para alguns tipos de criptografias que utilizam blocos de tamanhos particulares. 


\section{Tipo de carga útil (payload type)}

Este campo é utilizado pela aplicação do receptor para determinar como os dados devem ser tratados. A interpretação dos dados contidos na carga útil é definida por um perfil RTP. Este perfil é um número que define a especificação do formato contido no campo, por exemplo, um tipo especial de compressão. Este perfil, chamado de perfil de áudio e vídeo é uma tabela estática que define o número contido no campo para cada tipo de formato. Alguns exemplos de tipos de carga útil são apresentados na tabela 2.1.

\begin{tabular}{|c|c|c|c|}
\hline Tipo & Formato & Especificação & Descrição \\
\hline 0 & AUDIO/PCMUR & RFC 1890 & ITU G.711 00b5-law audio \\
\hline 3 & AUDIO/GSM & RFC 1890 & GSM full-rate audio \\
\hline 8 & AUDIO/PCMA & RFC 1890 & G.711 A-law audio \\
\hline 12 & AUDIO/QCELP & RFC 2658 & PureVoice QCELP audio \\
\hline 14 & AUDIO/MPA & RFC 2250 & MPEG audio (e.g., MP3) \\
\hline 26 & VIDEO/JPEG & RFC 2435 & Motion JPEG video \\
\hline 31 & VIDEO/H261 & RFC 2032 & ITU H.261 video \\
\hline 32 & VIDEO/MPV & RFC 2250 & MPEG I/II video \\
\hline
\end{tabular}

Tabela 2.1: Exemplos de tipos de payload type

\section{Número de sequência}

O número de sequência é utilizado para identificar pacotes e indicar ao receptor se algum pacote foi perdido ou entregue fora de ordem. O número de sequência é composto de um inteiro de 16 bits que é incrementado em um a cada pacote gerado e retorna a zero quando o valor máximo é atingido. Este número deve sempre apresentar uma sequência contínua, sendo incrementado a cada pacote e nunca repetir ou pular números, exceto no caso de atingir o valor máximo e zerar. O principal uso do número de sequência é a detecção de erros. Um número de sequência faltante em um fluxo de pacotes RTP indica uma perda na rede e a aplicação deverá tratar este problema. Este valor também pode ser utilizado para fazer a reordenação dos pacotes. Muitas vezes o receptor não precisa se importar com isso pois muitos decodificadores conseguem extrair o conteúdo mesmo com pacotes desordenados. 


\section{Timestamp}

O campo timestamp do protocolo RTP define o instante em que o primeiro octeto de dados do pacote foi criado. O timestamp é um número inteiro de 32 bits que é incrementado de acordo com a mídia que está sendo transportada e zera quando seu valor máximo é alcançado. A freqüência do clock é definida de maneira diversa para cada tipo de payload. Por exemplo, o payload no H.261 usa um clock de 90 $\mathrm{kHZ}$ para o timestamp. Para a maioria dos codecs de áudio, a freqüência do clock RTP é colocada em $8000 \mathrm{~Hz}$. O clock é sempre inicializado com um vetor aleatório e alimenta um contador de pulsos de clock. Se o payload contiver vídeo, o timestamp desse pacote RTP será o valor da contagem de pulsos de clock no instante em que foi obtido o primeiro quadro de vídeo codificado inserido no payload desse pacote. No caso de áudio, o timestamp RTP é o valor da contagem de pulsos de clock no momento em que a primeira amostra de áudio contida no payload foi produzida.

\section{Synchronization Source SSRC}

O campo SSRC synchronization source identifica os participantes de uma sessão RTP. É composto de um número inteiro de 32 bits escolhido aleatoriamente pelos participantes quando entram em uma sessão. Como os valores de SSRC são gerados localmente, dois participantes podem ter selecionado o mesmo valor. Esse tipo de colisão deve ser identificado pela aplicação quando ocorrer. Se um participante gerar múltiplos fluxos numa mesma sessão RTP, como vídeos e áudio separados, esses devem ser identificados com valores diferentes de SSRC, só assim o receptor conseguirá distinguir os pacotes de cada fluxo.

\section{Contributing source CSRC}

Sob circunstâncias normais, um fluxo RTP é gerado por uma única fonte, mas quanto temos múltiplos fluxos que passam por um mixer, utilizamos o campo contributing sources (CSRCs). Este campo identifica todos os participantes que contribuíram para a criação de um fluxo RTP. O servidor insere uma lista de identificadores SSRC das origens que contribuíram para a geração de um fluxo de pacotes. Esta lista é chamada de lista CSRC. Um exemplo de aplicação é uma áudio-conferência onde um servidor indica todos os sons vindos de diferentes microfones e produz somente um fluxo de 
pacotes para transmissão, permitindo que o receptor identifique quem é que está se comunicando no momento, mesmo que todos pacotes de áudio contenham o mesmo identificador SSRC.

\subsection{Soluções de Gerenciamento de Redes}

Gerenciamento é o processo de controlar uma rede de modo a maximizar sua eficiência e produtividade. Nenhuma rede hoje em produção pode viver sem um sistema adequado de gerência. A complexidade e o próprio custo de operação e manutenção das redes atuais fazem com que o investimento em gerenciamento seja prioritário para 0 oferecimento adequado de serviços de rede aos usuários finais. Atualmente, em operadoras de telecomunicações, é comum haver uma rede dedicada para gerência dos equipamentos e serviços, independente da rede de produção. $O$ caso de uma rede de TV Digital não é diferente, e as características desta rede e sua possível convergência com outras redes nos leva a crer que muitos desafios devam ser superados para que o gerenciamento da mesma seja realizado corretamente (CARVALHO, 1993).

Tradicionalmente, o gerenciamento de redes é dividido em 5 áreas principais, chamadas de Áreas Funcionais de Gerenciamento (CARVALHO, 1993). Estas áreas funcionais e seus objetivos são apresentados abaixo:

- Gerenciamento de Falhas:

- detectar, reportar, isolar, corrigir e até mesmo antecipar falhas;

- manter logs de eventos de falha significativos.

- Gerenciamento de Desempenho:

- monitorar e reportar métricas de desempenho da rede;

- alterar condições de desempenho que estejam prejudicando o bom funcionamento da rede, de seus elementos ou mesmo de serviços.

- Gerenciamento de Contabilização:

- controlar a utilização dos recursos de rede; 
- atribuir custos relativos à utilização de recursos da rede, informando aos usuários os custos resultantes de sua utilização;

- limitar o consumo de alguns usuários ou aplicações;

- delimitar escalas de tarifação;

- emitir relatórios sobre a utilização da rede.

- Gerenciamento de Configuração:

- gerenciar o ciclo de vida do sistema e sua configuração associada;

- permitir que a troca de configuração de recursos de rede possa ser realizada para determinado fim (em caso de falha, melhoria de desempenho, atualização obrigatória etc.);

- coletar informações sobre a configuração da rede.

- Gerenciamento de Segurança:

- gerenciar os mecanismos e procedimentos que garantem proteção aos recursos de rede;

- manter e manipular registros de segurança;

- realizar controle e armazenamenlo de chaves privadas e públicas utilizadas na rede por seus usuários.

\subsubsection{Arquiteturas de gerenciamento de redes}

Existe um grande número de protocolos para dar suporte às redes de computadores e ao gerenciamento de dispositivos de rede. Os exemplos mais comuns de protocolos de gerência de redes de computadores são o SNMP, WBEM, CMIP, WMI, Common Information Model, Transaction Language 1, JMX e netconf. Segue abaixo a descrição dos protocolos de gerência mais populares atualmente.

\section{SNMP}

A arquitetura SNMP (Simple Network Management Protocol) é a mais utilizada atualmente para o gerenciamento de redes IP. Ela foi desenvolvida a partir de conceitos e 
princípios simples e também opera de modo simplificado. Esta simplicidade foi o fator responsável por levar o SNMP rapidamente ao topo do mercado, pois esta arquitetura se mostrou capaz de resolver problemas de gerenciamento existentes nas redes da época a custos baixos e com baixo tempo de implantação (STALLINGS, 1998).

O SNMP está em sua versão 3 e teve sua primeira versão aceita como padrão oficial do Internet Enginnering Task Force (IETF) em 1990. Sua versão 2 foi publicada em 1993 porém foi pouco utilizada e substituida rapidamente pela versão 3. Esta última versão foi especificada em 1999 e se tornou um padrão oficial do IETF em 2002 (CARVALHO, 1993). O SNMP é o nome dado ao protocolo de gerência, mas acaba representando a própria arquitetura, formada pelos seguintes componentes:

- Gerente: controla as operações de gerenciamento e comunicação com os Agentes utilizando o protocolo SNMP, é possível também ter comunicação entre Gerentes para criar uma arquitetura descentralizada;

- Agentes: entidades de software que rodam nos recursos a serem gerenciados e respondem ao Gerente a eventos de gerenciamento. Os Agentes também enviam traps aos gerentes, que são eventos assíncronos que indicam que uma situação limite foi atingida em determinado recurso;

- Base de Informação de Gerenciamento - MIB (Management Information Base): é na verdade uma coleção de variáveis que descrevem o estado de recursos ou serviços da rede. As MIBs são definidas pelo Internet Engineering Task Force (IETF) e hoje existem milhares delas; as mesmas são globais, isto é, existe uma hierarquia global que deve ser respeitada onde fica determinada uma posição exata e um número de identificação para que cada nova variável projetada seja inserida. Existem MIBs para diversas aplicações, por exemplo podemos citar o controle de dispositivos de Domain Name Servers (DNS), servidores de Hyper Text Transfer Protocol (HTTP), impressoras e até mesmo set-top boxes para TV Digital;

- Protocolo de Comunicação: o SNMP define primitivas para comunicação entre Gerente e Agente e transporta as informações de gerenciamento sobre o protocolo User Datagram Protocol(UDP). O SNMP possui operações tanto de polling como de request/response.

Por ser a mais difundida das arquiteturas de gerenciamento de redes, a arquitetura SNMP, apesar de não ser a mais adequada para alguns ambientes, não deve ser ig- 
norada em nenhum projeto de gerenciamento para que, no mínimo, a compatibilidade com sistemas e produtos existentes seja preservada.

\section{WBEM}

Um dos principais problemas do SNMP, além da segurança limitada citada anteriormente, é o fato de o mesmo ser dependente de plataforma e por conta disto não prover muita interação entre diferentes plataformas. Este foi um dos motivos, entre outros, que levaram ao desenvolvimento da arquitetura Web-Based Enterprise Management (WBEM), baseada em padrões da Internet. O Distributed Management Task-Force (DMTF), órgão responsável pelas especificações WBEM, primeiro desenvolveu esta arquitetura para gerenciar, via Web, elementos de uma rede corporativa (terminais, servidores etc.). Com o grande crescimento da Internet e consequentemente de sistemas Web, o WBEM, após as primeiras especificações em 1997 cresceu e agora abrange uma solução completa de gerenciamento. Hoje o DMTF é um órgão cujos participantes são as grandes empresas de informática e redes (CARVALHO, 1993).

O seu objetivo principal é realizar o gerenciamento de elementos via browser. Mais do que isto, ter como ponto forte a utilização de protocolos já utilizados na Internet (portanto bastante conhecidos) e também a alta integração de plataformas por conta do uso destes protocolos. Os principais pontos da filosofia WBEM são:

- O uso de um modelo de dados completo e extensível, que permita conhecer o estado de um recurso e tambem manipulá-lo;

- Uma arquitetura do lado do cliente que permita que o mesmo possua alguma independência e inteligência sobre o processo de gerenciamento;

- A utilização de um protocolo de comunicação com uso em escala mundial, com possibilidade de transportar tanto objetos como operações de gerenciamento.

Com estes princípios em mente, a arquitetura WBEM foi desenvolvida mantendo os conceitos de Agente e Gerente apresentados no SNMP, porém a mesma utiliza o HTTP como protocolo de comunicação e sua base de informação (MIB) é escrita em Extensible Markup Language (XML) sendo que as operações WBEM também são escritas em XML e transportadas por HTTP. Esta base de informação, em sistemas 
WBEM, é chamada de Common Information Model (CIM). A mesma, diferentemente das MIBs SNMP, é orientada a objetos, ou seja, possui mecanismos como herança, relacionamentos, definição de métodos etc., o que representa um enorme ganho de inteligência no Agente, descentralizando deste modo a arquitetura.

Para se ter acesso ao CIM e a outras operações de gerenciamento, o Agente gerenciado incorpora uma entidade, chamada de Common Information Model Object Manager (CIMOM), que realiza a interface com o mundo externo. O CIM, apesar de apresentar várias inovações com relação às MIBs tradicionais, ainda é um dos pontos de resistência para a entrada de sistema WBEM no mercado, pois com o uso do CIM existe a necessidade de se reescrever as MIBs de vários equipamentos para CIM. Atualmente, conversores MIB - CIM existem para realizar este trabalho automaticamente, facilitando a transição.

Os objetos CIM são organizados através de uma estrutura chamada de CIM Schema. Este, na verdade, define uma hierarquia para a definição de objetos, e é dividido em três partes principals:

- Core schema: classes de mais alto nível com suas propriedades e relacionamentos;

- Common schema: classes genéricas de elementos específicos, por exemplo, aplicações, bancos de dados. redes de computadores etc. Não representam informações particulares de nenhum fabricante;

- Extension schemas: classes que representam informações específicas de fabricantes.

Caso o WBEM fosse usado para o gerenciamento de uma rede de TV Digital, deveriam ser desenvolvidos tanto um common schema genérico para os dispositivos que formam esta rede como também varios extension schemas, um de cada fabricante.

Com relação aos mecanismos de segurana, o WBEM utiliza protocolos padrões da WEB, como o Secure Socket Layer (SSL) e pode também apresentar mecanismos de autenticação e autorização como os utilizados na Internet. 


\section{JMX - Java Management Extensions}

A linguagem Java possui uma API específica para auxílio no desenvolvimento de aplicações de gerenciamento de redes chamada de JMX, que fornece a capacidade de gerenciar qualquer aplicação Java, através da disponibilização de vários serviços exclusivos para este fim, tentando ao máximo manter a compatibilidade com as arquiteturas de gerenciamento existentes atualmente. Hoje a arquitetura JMX é compatível com SNMP, WBEM e Common Request Broker Architecture (CORBA). Para fazer com que uma aplicação Java passe a ser gerenciável, a arquitetura JMX exige apenas a adição de 3 a 5 linhas de código por aplicação. Obviamente, a arquitetura JMX exige o uso de uma máquina virtual Java (JVM) rodando no Agente e também no Gerente (SUN MICROSYSTEMS, 2006). A arquitetura JMX é organizada em 3 níveis:

- Nível de Instrumentação - realiza a comunicação com o recurso ou o objeto Java a ser gerenciado. Este recurso ou objeto Java a ser gerenciado é chamado de Managed Bean (Mbean), e é uma espécie de invólucro JMX que é aplicado sobre estes elementos. O interessante é que este invólucro JMX pode ser aplicado sobre aplicações que não foram escritas em Java, preservando assim a compatibilidade com aplicações legadas ou de outra natureza;

- Nível de Agente - um Agente Java é desenhado para ser executado em um recurso gerenciável e fornecer serviços de gerenciamento. Um agente JMX possui um servidor Mbean (responsável pelos registros de Mbeans pertencentes a um recurso ou a uma aplicação), vários adaptadores de protocolo (responsáveis pela tradução de várias arquiteturas de gerenciamento em JMX (como SNMP ou XML/HTTP) e vários conectores, que fornecem comunicação JMX (sobre HTTP/HTTPS) fim-a-fim;

- Nível de Gerente - realiza o controle das operações de gerenciamento e agrupa os agentes de modo que o gerenciamento possa ser organizado do modo correto.

Complementando esta arquitetura, o JMX ainda fornece alguns serviços básicos para serem utilizados por aplicações de gerenciamento, entre estes:

- Registro de Mbeans;

- Descobrimento de Mbeans; 
- Criação de relacionamentos e dependências entre Mbeans;

- Descobrimento de agentes e gerentes;

- Segurança

Para auxiliar no processo de construção de aplicações de gerenciamento baseadas em JMX, e para manter a compatibilidade com a especificação, o JMX fornece também ferramentas para testes de conformidade, para que o desenvolvedor possa escrever a aplicação corretamente e para que ele possa ser portada sem problemas para outros ambientes (CARVALHO, 1993).

Atualmente, a tecnologia JMX é utilizada e aceita amplamente por aplicações de gerenciamento, sendo que várias ferramentas para desenvolvimento estão disponíveis. Apesar destas facilidades, da compatibilidade com arquiteturas existentes e da vantagem da mesma ser escrita em Java, linguagem amplamente conhecida, a mesma ainda não apresenta um grande número de serviços de gerenciamento prontos para uso do desenvolvedor.

\section{CORBA}

O padrão CORBA (Common Object Request Arquitecture Broker) é um modelo proposto pela OMG (Object Management Group), com o objetivo de promover a tecnologia de objetos distribuídos, é uma estrutura comum para o desenvolvimento independente de aplicações, usando técnicas de orientação a objeto em redes de computadores heterogêneas. O padrão visa diminuir consideravelmente os custos, reduzir a complexidade, e proporcionar caminhos para o surgimento de novas aplicações a partir dos conceitos propostos pela OMG. Resumidamente, o CORBA propõe a interoperabilidade local ou remota entre aplicações, independente das linguagens de programação em que foram desenvolvidas e sobre quais plataformas serão executadas (DITTRICH, 1997).

Uma aplicação do modelo CORBA é promover a intercomunicação de objetos distribuídos em uma rede de computadores afim de executar alguma tarefa específica. Entretanto, o CORBA é apenas uma parte de uma outra tecnologia também proposta pela OMG, a OMA (Object Management Architecture), a qual compreende quatro componentes, descritos da seguinte maneira: 
- ORB (Object Request Broker): componente definidor do barramento comum para a troca de mensagens entre os objetos;

- Objetos de Serviços comuns (Common Object Services): serviços implementados por objetos do sistema, utilizados para ampliar a funcionalidade do barramento de objetos (ORB);

- Facilidades Comuns: definem facilidades e interfaces no nível de aplicação;

- Objetos de Aplicação: são os objetos em si, específicos para cada aplicação ou sistema distribuído;

- Interfaces de domínio: padronização de objetos que permite sua comunicação.

O ORB exerce o papel de middleware entre os componentes, e é responsável por toda comunicação e interação entre os objetos. Ele intercepta a chamada e fica responsável em encontrar um objeto que atenda às necessidades do pedido. Encontrando o objeto, o ORB passa os parâmetros para o mesmo, invoca os métodos necessários dele e retorna para o objeto que solicitou o pedido os resultados de todo esse procedimento. Dessa maneira, o usuário não precisa se preocupar onde tal objeto está localizado, em que sistema operacional ele roda ou qual programa foi usado para desenvolvê-lo.

Os Objetos de Serviços comuns gerenciam os objetos (criação, controle e rastreamento). Quanto aos Objetos de Aplicação e Facilidades Comuns, pode-se dizer que são componentes que estão mais diretamente relacionados com o usuário final, estando intimamente ligados com as invocações dos serviços que o sistema de cada usuário necessite.

Os objetos distribuídos CORBA são pequenas partes código de um sistema maior. Essas pequenas partes estão distribuídas na rede, e apresentam-se como componentes binários que podem ser acessados por meio de métodos de invocação. Os objetos clientes podem ser remotos ou não (DITTRICH, 1997).

Para a ocorrência das conhecidas características dos objetos distribuídos, o CORBA dispõe de um meio que padroniza os objetos, permitindo sua comunicação: a utilização de interfaces. Cada objeto tem uma interface definida, que deve conhecer e saber requisitar um serviço a outro objeto. Desta maneira, não se faz necessário saber detalhes de sua implementação (código) para que o objeto possa ser acessado. Para 


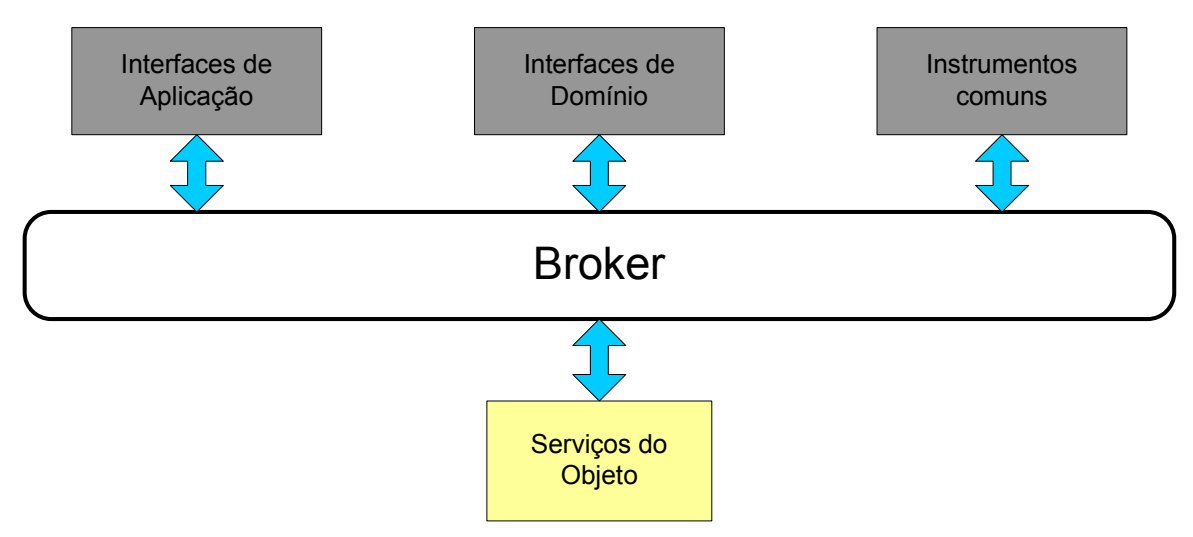

Figura 2.13: Arquitetura do Modelo de Referência da OMG

especificar essa interface dos objetos, a OMG utiliza uma IDL (Interface Definition Language), que define interfaces aos objetos nesta rede.

Com a definição das interfaces, o objeto cliente acessa um outro objeto pela execução de uma requisição (evento) ao mesmo, o qual tem suas características conhecidas por todos através de sua interface, que por sua vez é conhecida por ser gerada a partir do padrão IDL, utilizado por todos os objetos da OMG. Em virtude disso, torna-se possível a interação entre diferentes objetos. A figura 2.13, mostra melhor a Arquitetura do Modelo de Referência da OMG.

\subsubsection{Soluções de gerenciamento por domínio}

As arquiteturas de rede utilizadas atualmente, a exemplo das que integram os sistemas de TV Digital às redes de computadores, são heterogêneas, fazendo com que o principal desafio para gerenciar o sistema como um todo seja esta heterogeneidade. Para atingir um nível adequado de qualidade de serviço, é necessário gerenciar corretamente a rede que irá transportar fluxos de áudio, vídeo e dados. A tabela 2.2 enumera os principais tipos de redes e as soluções de gerenciamento existentes para cada uma delas. A partir desta análise é possível definir um conjunto de soluções que satisfaçam as necessidades de gerenciamento da rede do sistema.

Como mostra a tabela 2.2, roteadores de redes ATM e IP em sua maioria utilizam o protocolo SNMP e alguns também possuem soluções WBEM, e atualmente, com a popularização de protocolos como o SNMP, muito poucos utilizam uma solução proprietária (THOMPSON, 1998). Codificadores e decodificadores usam muitas vezes 


\begin{tabular}{|c|c|c|c|c|}
\hline & Roteadores & Cod/Decod & Transmissores de Rádio & Monitor RTP \\
\hline TMN & & & $\mathrm{X}$ & \\
\hline SNMP & $\mathrm{X}$ & $\mathrm{X}$ & & $\mathrm{X}$ \\
\hline WBEM & $\mathrm{X}$ & $\mathrm{X}$ & & $\mathrm{X}$ \\
\hline Proprietário & $\mathrm{X}$ & $\mathrm{X}$ & $\mathrm{X}$ & \\
\hline
\end{tabular}

Tabela 2.2: Soluções de gerência mais comuns

soluções proprietárias mas já existem equipamentos que implementam o SNMP e também o WBEM. Transmissores de rádio-frequência utilizam uma grande variedade de soluções de gerência, em sua maioria, proprietárias. Geralmente informações como atenuação e ruído do meio de transmissão são gerenciados por este tipo de equipamento.

A partir dessa análise a arquitetura SNMP de gerência de redes foi selecionada para ser implementada no sistema de monitoramento deste trabalho em função de se mostrar a mais utilizada atualmente pela maioria dos equipamentos de rede e aplicações, e conter uma base de informações de gerência específica para o protocolo RTP necessárias para o sistema implementado.

\subsection{RTP Management Information Base (MIB)}

A base de informações de gerência RTP (RTP-MIB) define um objeto da arquitetura SNMP para gerenciamento de sistemas RTP. Este trabalho é de autoria do grupo de transporte de vídeo (AVT) do IETF (Engineering Task Force) (BAUGHER et al., 1999) para ser utilizado como base para todas aplicações que coletam estatísticas RTP. Este capítulo descreve alguns conceitos básicos da RTP-MIB (BAUGHER et al., 2000). Os objetos gerenciáveis pela RTP-MIB são estruturados em três tipos de informação:

- Informações gerais das sessões RTP como seus endereços;

- Informações sobre um fluxo RTP sendo enviado por um transmissor específico;

- Informações sobre um fluxo enviado de um transmissor para um receptor específico.

Exitem dois tipos de dispositivos num sistema RTP: os hosts e os monitores. Os hosts RTP são os dispositivos finais que podem utilizar a MIB-RTP para coletar dados sobre 
as sessões e os fluxos de dados que estão enviando ou recebendo. Esses dados podem ser utilizados por um Gerente de rede para detectar e diagnosticar falhas que ocorrem durante uma sessão RTP. Os monitores RTP podem ser equipamentos que retransmitem pacotes RTP na rede. Eles podem utilizar a MIB RTP para coletar dados estatísticos das sessões RTP. Estas informações podem ser utilizadas por um gerente de redes para detectar falhas e permitir a configuração da operação da rede.

Um dispositivo RTP pode ser um equipamento que envia ou recebe pacotes de dados RTP, ou pode ser um dispositivo que somente passa adiante os pacotes recebidos. $O$ agente que implementa a MIB RTP pode estar tanto nos dispositivos finais, como set-up boxes e aparelhos celular, como nos roteadores nos quais os fluxos de vídeo passam entre o servidor e o usuário final. Estes podem ser chamados de Monitores RTP. O objetivo é coletar dados sobre a situação das sessões RTP e seus fluxos para fins de monitoramento e diagnóstico de falhas. Cada agente possui uma MIB que pode ser requisitada por um gerente (BAUGHER et al., 2000). A RTP-MIB é estruturada em três tabelas principais: tabela de sessão, tabela do receptor e tabela do transmissor como demonstrado na figura 2.14 .

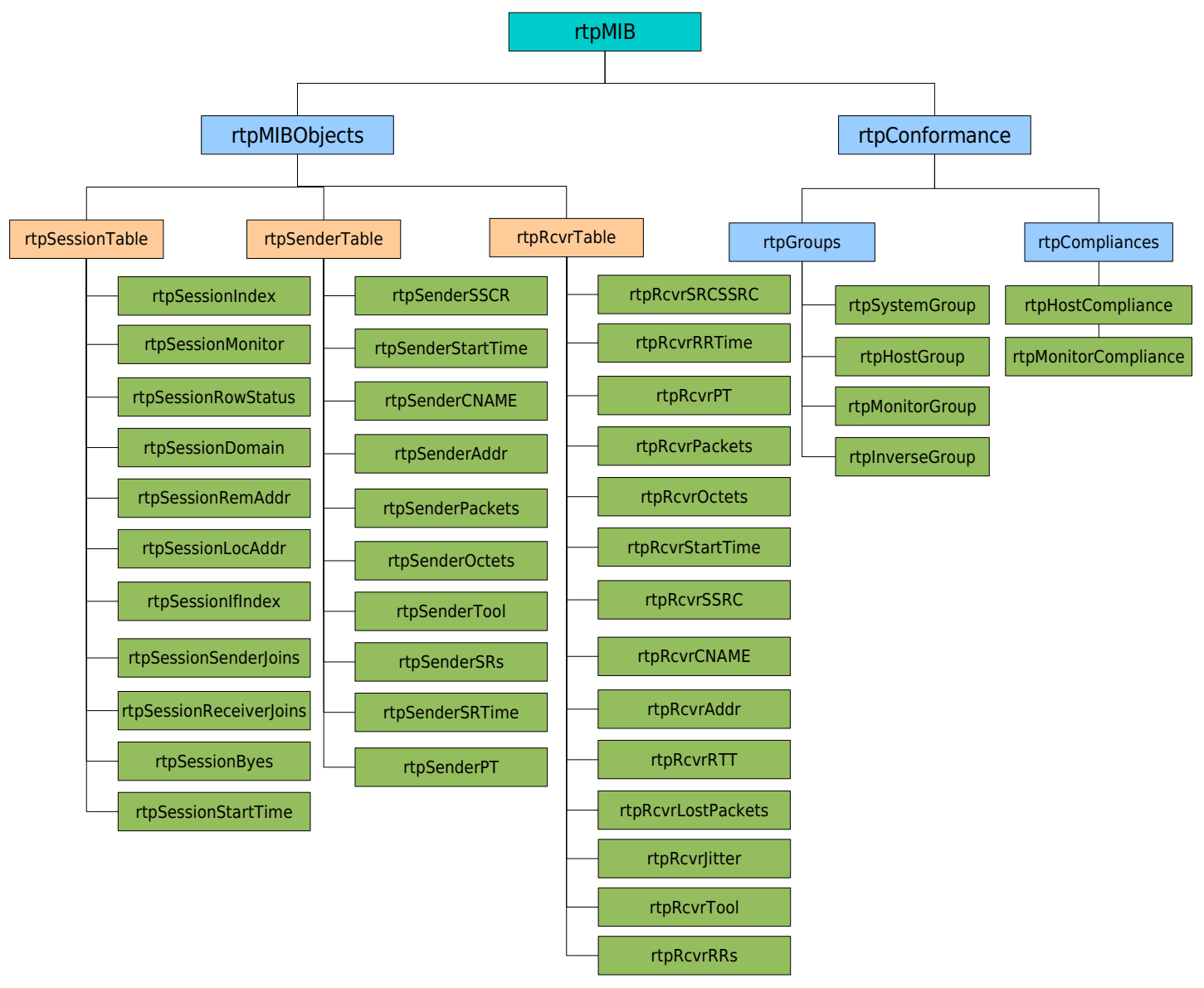

Figura 2.14: Hierarquia da MIB RTP 


\subsection{1 rtpSessionTable}

A rtpSessionTable contém objetos que descrevem as sessões RTP ativas em um host, sistema intermediário ou monitor. Abaixo são descritos os objetos contidos nesta sessão segundo (BAUGHER et al., 2000; SCHULZRINNE et al., 2003).

rtpSessionIndex Índice de cada linha da tabela. É utilizando somente pelo SNMP e não tem nenhuma ligação com o protocolo RTP;

rtpSessionMonitor Valor booleano que indica se transmissores e receptores remotos estão sendo monitorados por RTCP. Monitores RTP devem apresentar este valor como 1 e hosts RTP devem ter valor 2.

rtpSessionRowStatus Estado no qual uma nova linha da tabela pode se encotrar. Uma nova linha deve ter todos seus objetos inicializados para entrar no estado ativo.

rtpSessionDomain Define o protocolo de transporte utilizado para enviar e receber o fluxo RTP nesta sessão;

rtpSessionRemAddr Contém o endereço do destino para o qual o fluxo RTP está sendo enviado e/ou recebido. Em uma sessão RTP multicast, este é o único endereço utilizado por todos transmissores e receptores. Em uma sessão unicast, este é o endereço do sistema RTP remoto.

rtpSessionLocAddr Contém o endereço local utilizado no sistema RTP. Em uma sessão RTP multicast, rtpSessionRemAddr será igual ao rtpSessionLocAddr. Em uma transmissão unicast, rtpSessionRemAddr e rtpSessionLocAddr terão valores diferentes.

rtpSessionlfIndex Este valor é preenchido com o valor da IF-MIB. Esta é a interface para a qual o fluxo está sendo enviado;

rtpSessionSenderJoins Número de transmissores que entraram na sessão desde que esta foi criada (rtpSessionStartTime). Toda vez que um rtpSenderEntry é criado para essa sessão, este contador é incrementado;

rtpSessionReceiverJoins Número de receptores que entraram na sessão desde que esta foi criada (rtpSessionStartTime). Toda vez que um rtpRcvrEntry é criado para essa sessão, este contador é incrementado;

rtpSessionByes Contador de mensagens RTCP BYE recebidas por esta entidade; 
rtpSessionStartTime Valor do SysUpTime na hora que esta linha foi criada;

\subsection{2 rtpSenderTable}

Esta tabela contém informações sobre o transmissor ou os transmissores de uma sessão RTP. Todo dispositivo que esteja transmitindo um fluxo RTP deve ter uma linha nesta tabela. Os dispositivos monitores devem criar uma linha para cada transmissor que esteja sendo monitorado (BAUGHER et al., 2000; SCHULZRINNE et al., 2003).

rtpSenderEntry As entradas contém informações de cada RTP Synchronization Source. Linhas são removidas da tabela quanto uma mensagem BYE do RTCP é recebida do transmissor ou quando ocorre timeout.

rtpSenderSSRC Synchronization source identifier do transmissor. O endereço de uma sessão em conjunto com o SSRC identificam um fluxo RTP.

rtpSenderStartTime Valor do SysUpTime na hora que esta linha foi criada;

rtpSenderCNAME O nome canônico do transmissor RTP;

rtpSenderAddr $O$ endereço unicast da origem do transmissor;

rtpSenderPackets Contador de pacotes RTP enviados por este transmissor, ou observado por um monitor, desde o início da sessão (rtpSenderStartTime);

rtpSenderOctets Contador de octetos enviados por este transmissor, ou observado por um monitor, desde o início da sessão (rtpSenderStartTime);

rtpSenderTool Nome da aplicação da origem do fluxo;

rtpSenderSRs Contador do número de RTCP Sender Reports que foram enviados por este transmissor, ou observado por um monitor, desde o início da sessão (rtpSenderStartTime);

rtpSenderSRTime É o valor do SysUpTime no momento em que o último SR foi recebido deste transmissor, no caso de um host de monitoramento ou receptor;

rtpSenderPT Tipo de payload do cabaçalho RTP. 


\subsection{3 rtpRcvrTable}

Tabela de informações dos receptores de uma sessão RTP. Cada host que recebe um fluxo RTP cria uma entrada na tabela (BAUGHER et al., 2000; SCHULZRINNE et al., 2003).

rtpRcvrEntry Cada entrada contém informações de um único Synchronization Source SSRC. A sessão é identificada para uma entidade SNMP através do rtpSessionlndex. Estas entradas são removidas por um agente RTP quando este recebe uma mensagem BYE do protocolo RTCP ou quanto ocorre um timeout do transmissor.

rtpRcvrSRCSSRC Identificador do transmissor. Endereço de sessão RTP em conjunto com um SSRC único identificam um transmissor ou um receptor em um fluxo RTP;

rtpRcvrRRTime É o valor do SysUpTime no momento em que o último relatório RTCP foi recebido, no caso de um monitor ou receptor. E é o valor SysUpTime no momento em que o último RR foi enviado por este receptor;

rtpRcvrPT Tipo de payload do cabeçalho RTP;

rtpRcvrPackets Contador de pacotes recebidos por este receptor desde o rtpRcvrStartTime. Monitores não devem conter este valor e devem responder noSuchlnstance;

rtpRcvrOctets Contador de octetos recebidos por este receptor desde o momento rtpRcvrStartTime. Monitores não devem conter este valor e devem responder noSuchInstance;

rtpRcvrStartTime O valor do SysUpTime no momento em que esta entrada foi criada;

rtpRcvrSSRC O synchronization source identifier do receptor. Um endereço de sessão RTP em conjunto com o SSRC identificam um transmissor ou um receptor em um fluxo RTP;

rtpRcvrCNAME Nome canônico do receptor RTP;

rtpRcvrAddr O endereço de transporte unicast do receptor; 
rtpRcvrRTT O valor do round trip time obtido pela origem do fluxo RTP segundo o algoritmo descrito em (SCHULZRINNE et al., 2003). Este algoritmo pode produzir valores significantes quanto o agente apresenta o mesmo clock que o transmissor.

rtpRcvrLostPackets Um contador de pacotes RTP perdidos desde o rtpRcvrStartTime;

rtpRcvrJitter Valor estimado de variação de atrasos observado pelo receptor; rtpRcvrTool Nome da aplicação da origem do fluxo RTP;

rtpRRs Um contador de relatórios recebidos por este receptor desde rtpSessionStartTime.

O protocolo RTP e sua base de informações de gerência (MIB-RTP) dão subsidio para criar o Monitor RTP que tem como principal característica calcular a variação de atraso dos pacotes dos fluxos de mídia. Através da implementação do Monitor RTP é possível criar um sistema que permite determinar a variação de atraso nos pacotes do fluxo de TV Digital que atravessa a rede. Isto cria a possibilidade de monitorar requisitos de qualidade de serviço.

\subsection{Trabalhos Relacionados}

Esta sessão apresenta alguns trabalhos relacionados à monitoração através do RTP. Algumas destas ferramentas utilizam o protocolo RTCP e são principalmente utilizadas em transmissões multicast.

\subsubsection{Rtpmon}

O Rtpmon é um monitor RTP escrito em linguagem $\mathrm{C}_{++}$pelo Plateau Multimedia Research Group da universidade de Berkeley. O Rtpmon possui uma interface gráfica que permite ordenar, filtrar e mostrar estatísticas geradas por uma sessão RTP (BACHER et al., 1997). A figura 2.15 mostra a interface gráfica da ferramenta. Neste exemplo podemos ver uma lista de sessões RTP e estatísticas geradas a partir de 
mensagens RTCP adquiridas de uma sessão multicast. Informações de cada participante desta sessão podem ser obtidas clicando em seu respectivo nome na tabela de participantes. O Rtpmon pode também mostrar um pequeno histórico das estatísticas geradas para cada par transmissor-receptor.

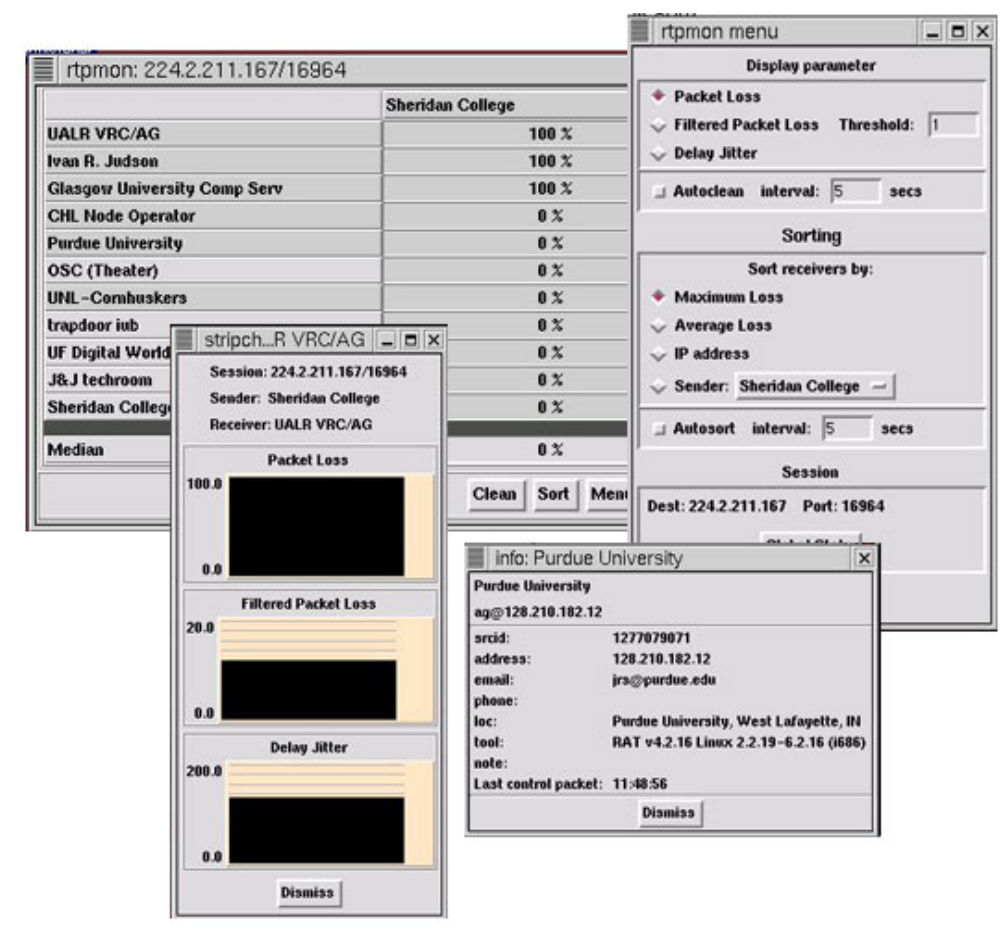

Figura 2.15: Interface gráfica do Rtpmon

\subsubsection{RTPMonitor}

O RTPMonitor é uma ferramenta desenvolvida para monitorar sessões RTP utilizando o Java Media Framework (JMF). Esta ferramenta foi desenvolvida com o objetivo de monitorar os fluxos RTP e é um componente do protocolo VRTP (Virtual Reality Transfer Protocol), protocolo desenvolvido para suportar ambientes virtuais (LSVE - largescale virtual environments) na Internet. A figura 2.16 mostra a interface gráfica do Rtpmonitor. 


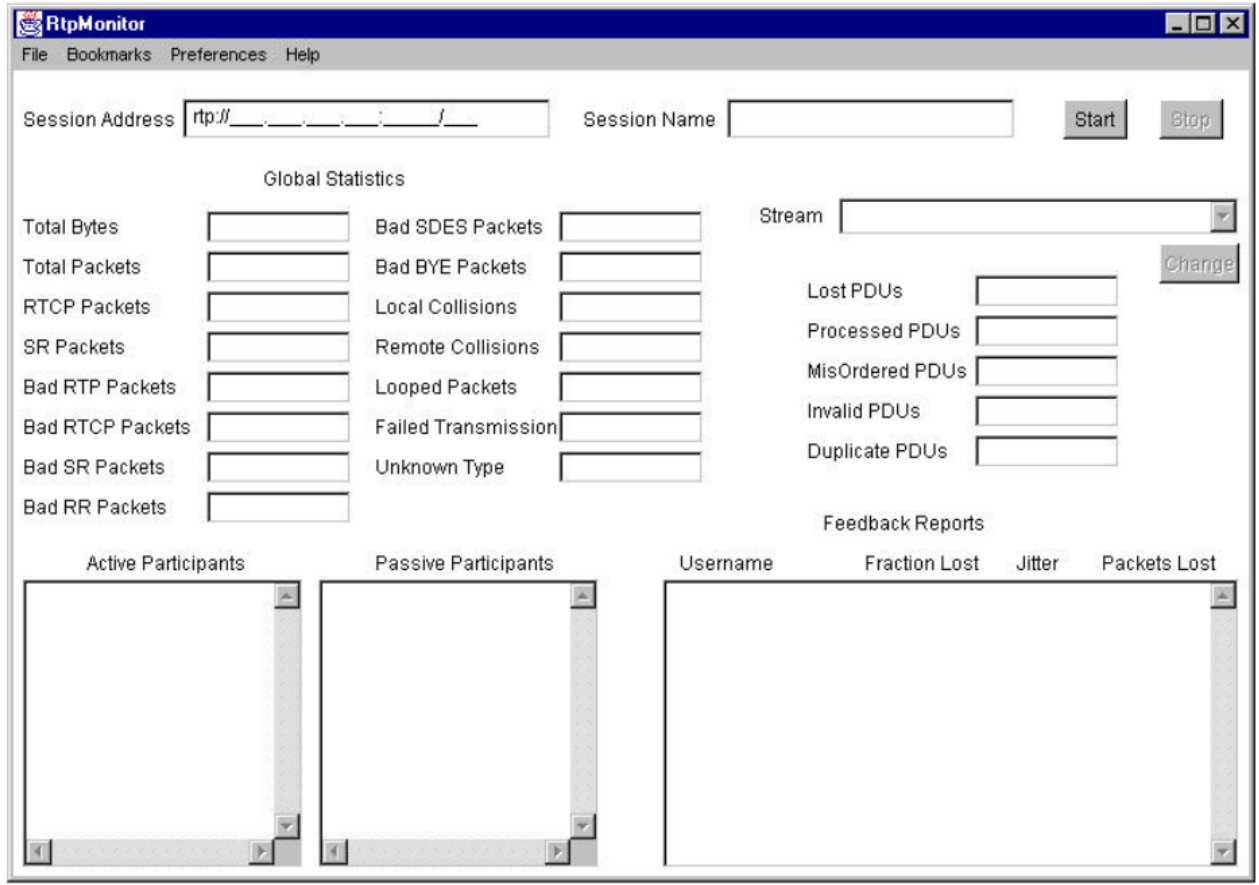

Figura 2.16: Interface gráfica do Rtpmonitor 


\section{Sistema de monitoramento de transmissão de TV Digital}

O principal objetivo do Sistema de Monitoramento é alimentar o sistema de Controle de QoS. Neste capítulo será apresentado, de modo sucinto, o Sistema de Controle de QoS e, em seguida, o Sistema de Monitoramento.

\subsection{Sistema de Controle de QoS}

Esse sistema é responsável pelo controle de Qualidade de Serviço de cada domínio administrativo. As principais funções deste elemento são:

- Construir um modelo de rede baseado em informações armazenadas pelo sistema de gerência de redes;

- Negociar fluxos de mídia entre os domínios administrativos;

- Mapear parâmetros de QoS em descritores de fluxo;

- Reagir a qualquer mudança na rede que comprometa a Qualidade de Serviço.

Para isso o sistema de controle de QoS necessita de informações do estado da rede onde os fluxos de dados irão trafegar. Estas informações devem ser adquiridas pelo Sistema de Monitoramento através dos agentes e dos monitores RTP. Algumas informações relevantes para o sistema de controle de QoS são:

- Informações de carga em cada link; 
- Atraso em cada link;

- Variação de atraso em cada link;

- Taxa de perda de pacotes;

- Estado do equipamento (memória, processador etc.)

\subsection{Objetivos do Sistema de Monitoramento}

O sistema de monitoramento proposto é responsável por alimentar a arquitetura de controle de QoS. Em cada sistema apresentado (Figura 3.1) haverá um subsistema de gerenciamento de domínio responsável por monitorar e controlar os equipamentos de rede dentro de cada domínio administrativo de rede. Além disso, todas as informações referentes às condições da rede, como configuração de equipamentos, carga de processamento, estado dos links, entre outras, serão conhecidas pelo Sistema de Gerenciamento de Domínio (SGD). O SGD obtém informações através do protocolo de gerenciamento SNMP dos agentes instalados nos equipamentos. Outro componente nesta infraestrutura, chamado de monitor RTP, alimenta o SGD com informações referentes à transmissão dos fluxos RTP nos diversos domínios até a transmissão por difusão aérea.

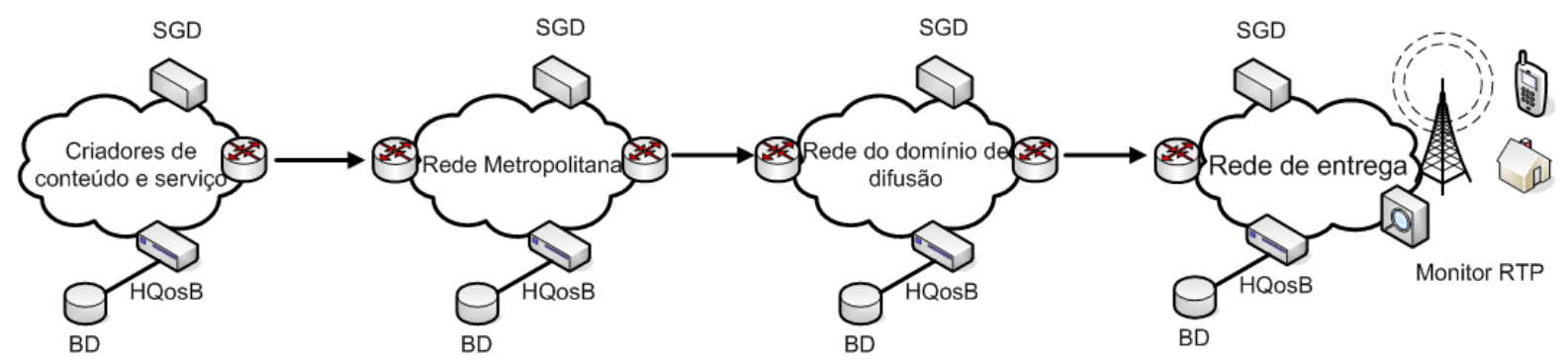

Figura 3.1: Visão simplificada da arquitetura

Os principais objetivos deste sistema de monitoração são:

- Prover informações sobre os fluxos de transmissão de mídia para o sistema de controle de QoS (representado pelo HQoSB da figura 3.1);

- Alimentar a base de dados de engenharia de tráfego (representado pelo BD da figura 3.1); 
- Disponibilizar informações de gerência de redes para os principais provedores de conteúdo do sistema (SCCs e SSs).

Os sistemas de gerenciamento geralmente são utilizados para gerenciamento de nível de serviço (SLM), isto é, o sistema deve monitorar os parâmetros de rede e comparálos com os dados especificados pelo SLA contratados pelos SCCs e SSs. No sistema proposto, deve ser feito com as informações obtidas pelos SGDs. Confrontando os valores especificados pelo SLA com dados relativos às condições da rede (Taxa de transmissão, Atraso, Variação de atraso, Perda de pacotes) obtidos pelos SGDs, o sistema possui informações suficientes para o gerenciamento do nível de serviço.

\subsection{Apresentação do sistema de gerenciamento da rede}

O cenário mostrado na figura 3.2 considera três tipos de relacionamento, ou modelos de negócio, entre geradores de conteúdo e de serviços, criando três possibilidades de ambiente de rede. Para descrever como os componentes do sistema devem ser distribuídos em uma rede pública (diversos sistemas autônomos) devemos considerar esses três cenários que podem ser vistos na figura 3.2:

- Os Servidores de Criação de Conteúdo e os Servidores de Serviços possuem links dedicados entre eles (Área A);

- Os Servidores de Criação de Conteúdo e os Servidores de Serviços estão no mesmo domínio (Área B);

- Servidores de Criação de Conteúdo e os Servidores de Serviços tem domínios independentes que são conectados através de uma rede metropolitana IP (Área C).

Esses domínios e configurações são baseados em modelos de negócio e redes em funcionamento, sendo que o sistema proposto suporta todos os tipos de configuração mencionados. Abaixo está descrito em detalhes o posicionamento dos diversos dispositivos propostos pela arquitetura de gerenciamento. 


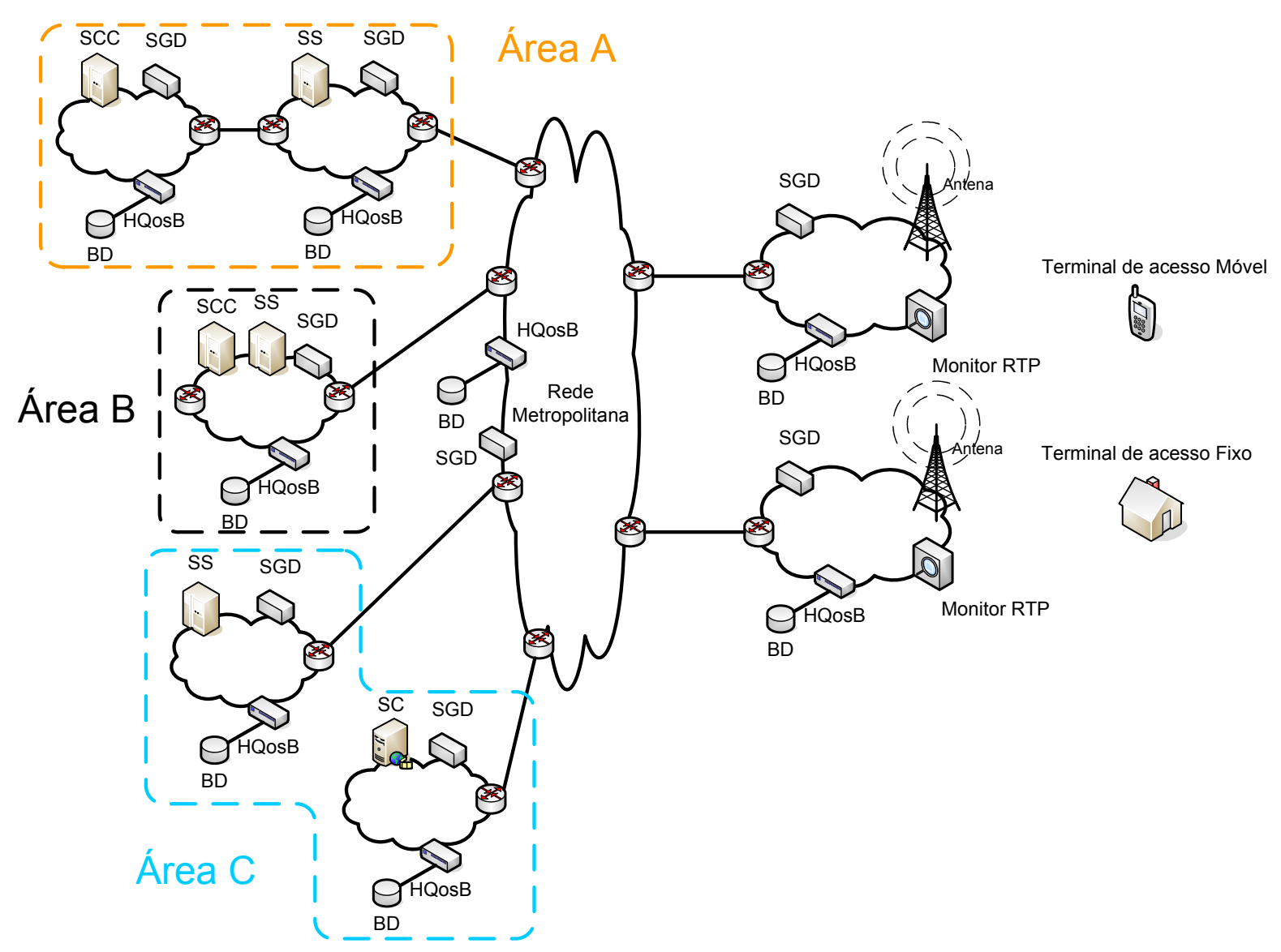

Figura 3.2: Arquitetura do sistema de gerenciamento em redes heterogêneas

- Os SGDs estão localizados em todos os domínios administrativos. O SGD é responsável pelo gerenciamento de rede de cada domínio. Estes dispositivos têm um papel fundamental no sistema de gerenciamento, pois são eles os responsáveis por obter informações desta rede e compartilhar com os outros subsistemas.

- Os elementos HQoSB são responsáveis por gerenciar e controlar os níveis de QoS da rede baseados em informações obtidas pelo sistema de gerenciamento SGD e dados de engenharia de tráfego armazenados nos bancos de dados (BD);

- Os monitores RTP são localizados principalmente nos segmentos nos quais as transmissões são feitas através de ondas de rádio. Estes dispositivos também podem ser utilizados em qualquer domínio que não tenha informações de qualidade de serviço relacionadas à transmissão de fluxo de mídia (atraso, variação de atraso e perda). Estes monitores utilizam informações extraídas do cabeçalho do protocolo de transporte RTP quando recebe um fluxo de mídia e serão descritos com mais detalhes adiante;

- BDs estão localizados em todos os domínios e são utilizados pelos HQoSB. 
Estes dispositivos possuem uma base de dados com informações obtidas dos equipamentos através de, por exemplo, requisições SNMP.

\subsection{Descrição e funcionalidade dos componentes}

O sistema de monitoramento proposto é composto por quatro subsistemas com funcionalidades específicas. O Subsistema de Gerenciamento de Domínio (SGD), responsável por gerenciar equipamentos de rede de um domínio administrativo, o HQoSB (Heterogeneous QoS Broker), responsável por controlar os recursos de rede de cada domínio administrativo e se comunicar com outros HQoSB em domínios administrativos diferentes, o monitor RTP, que é o analisador de fluxos RTP e por fim a Base de dados de engenharia de tráfego, onde ficam registrados parâmetros de qualidade de serviço da rede. Em conjunto, esses subsistemas constituem uma solução para gerenciamento de redes heterogêneas, e suas funcionalidades são descritas a seguir.

\subsubsection{Subsistema de Gerenciamento de Domínio - SGD}

Este subsistema é o componente principal do sistema de gerenciamento, e tem como principal objetivo gerenciar os equipamentos de rede de um certo domínio e trocar informações de gerenciamento entre domínios. Este subsistema apresenta funcionalidades muito similares às encontradas em sistemas de gerenciamento corporativos.

Como mostra a figura 3.3, o SGD recebe informações de todos os componentes do sistema e contém os parâmetros de SLA que foram especificados no ESG e pelos outros usuários que devem ser monitorados. Esses dados são então enviados para a base de dados de engenharia de tráfego e ao HQoSB que gerencia os níveis de qualidade de serviço na rede. O SGD fica monitorando a rede através de informações contidas nas MIBs de cada um dos equipamentos (servidores, roteadores, switches e monitores RTP) dentro do seu domínio e deve trocar mensagens com os SGDs de outros domínios administrativos.

A comunicação entre os SGDs de domínios distintos é necessária para garantir os acordos entre os principais provedores do sistema (SCC e SS) e somente através de informações de gerenciamento de rede é possível assegurar o SLA definido entre 
estes provedores.

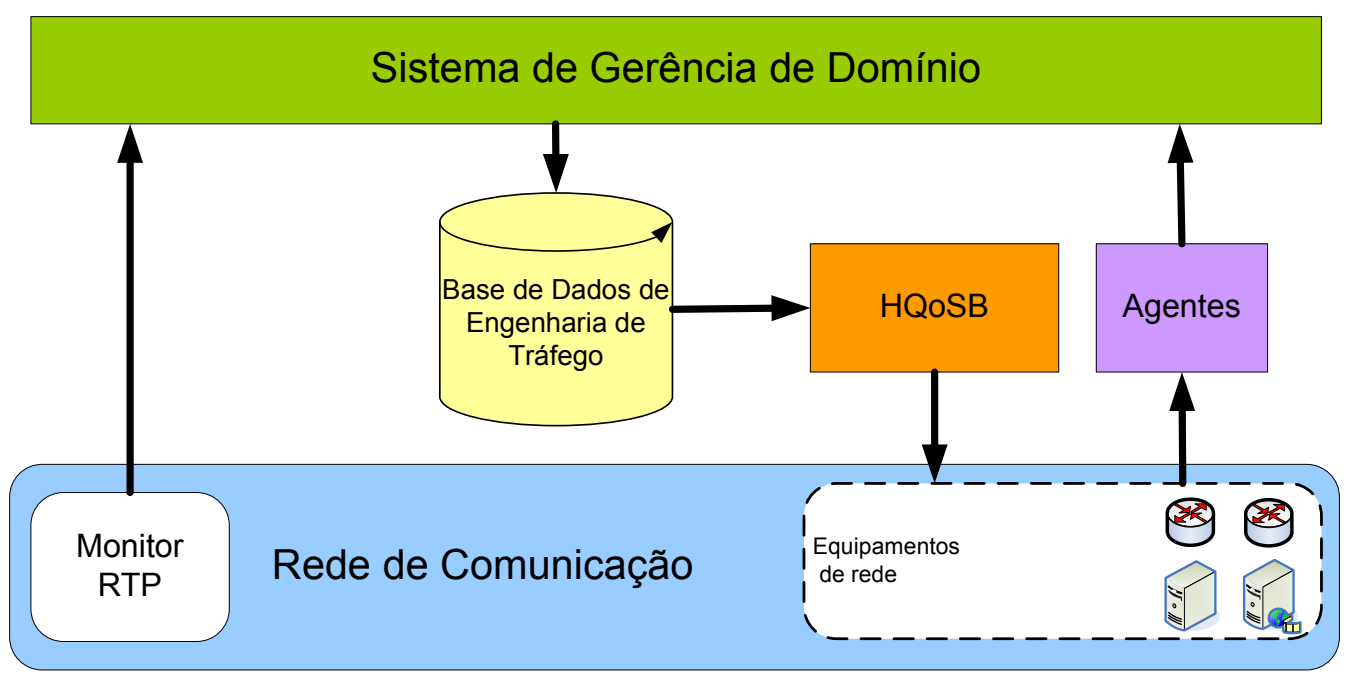

Figura 3.3: Arquitetura do Sistema de Monitoramento

Uma vez que os mecanismos para gerenciar e controlar a rede estiverem configurados, informações de QoS e tráfego devem ser armazenadas em um sistema de banco de dados a fim de prover à ferramenta de controle de QoS parâmetros para cálculos de rotas através de informações de estado do link e capacidade de transmissão adquiridos pelos SGDs. A base de dados deve ser constantemente atualizada pelos mecanismos de gerência de redes senão não será possível controlar os níveis de QoS exigidos pelas aplicações em tempo real.

\subsubsection{HQoSB - Heterogeneous QoS Broker}

O HQoSB é o Sistema de Controle de QoS e é responsável por controlar os recursos de cada domínio administrativo. É necessário que cada um desses domínios tenham pelo menos um HQoSB que controla todas configurações relacionadas à Qualidade de Serviço a fim de garantir que todos fluxos de mídia tenham tratamento apropriado.

Este sistema deve ser capaz de negociar fluxos de mídia entre os domínios administrativos e reagir a qualquer distúrbio na rede que comprometa a Qualidade de Serviço. Esses distúrbios devem ser detectados a partir de dados adquiridos pelo SGD através dos agentes e monitores RTP. 


\subsubsection{Monitor RTP}

O monitor RTP coleta os fluxos de transporte de mídia para medir atraso, variação de atraso e perda de pacotes e envia estas informações através de mensagens SNMP para o gerente ou SGD. Este componente da rede permite a monitoração de uma sessão RTP através da base de informações de gerência MIB-RTP a qual é obtida pelo cálculo das diferenças de atraso entre os pacotes RTP recebidos.

Os monitores RTP podem estar localizados em qualquer lugar da rede, basta que o fluxo de mídia possa ser capturado pela sua interface de rede. Deste modo, o monitor faz o cálculo da variação de atraso entre pacotes até este ponto da rede, como define o comportamento fim-a-fim do protocolo RTP. A figura 3.4 demonstra o posicionamento dos monitores RTP para que seja possível a obtenção do valor de variação de atraso em cada domínio administrativo da rede.

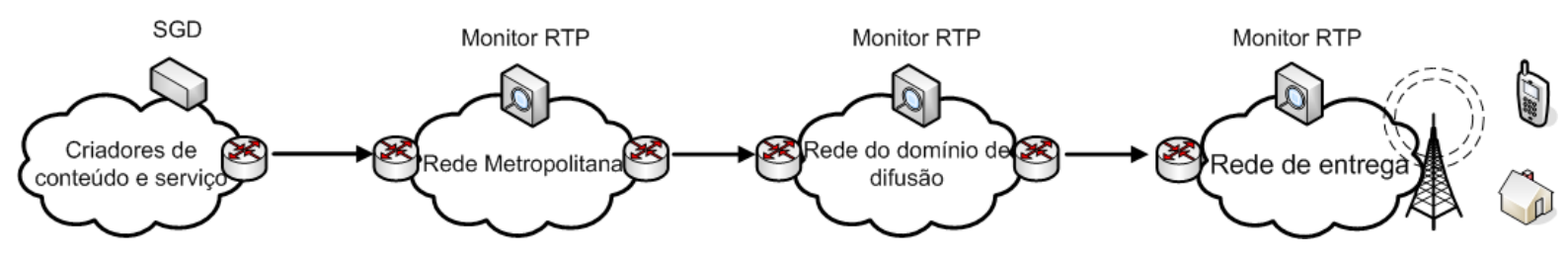

Figura 3.4: Posicionamento dos Monitores RTP na rede

De acordo com a RFC 3550 (SCHULZRINNE et al., 2003) o cálculo da variação de atraso entre os pacotes RTP recebidos pelo monitor pode ser calculada com base nos valores do campo timestamp e arrival dos pacotes. Se Si é o valor do timestamp do pacote i, e Ri é a hora de chegada deste pacote RTP (arrival), então, para dois pacotes i e j, a diferença $D$ pode ser expressa por:

$$
D(i, j)=(R j-R i)-(S j-S i)=(R j-S j)-(R i-S i)
$$

A variação de atraso deve ser calculada continuamente enquanto pacotes são recebidos no monitor utilizando a diferença $D$ entre o pacote atual e o anterior ( $i-1)$ em ordem de chegada de acordo com a fórmula:

$$
J(i)=J(i-1)+(|D(i-1, i)|-J(i-1)) / 16
$$


O cálculo da variação de atraso deve ser calculado conforme a fórmula especificada aqui. Este algoritmo é o que mais se aproxima do valor real de variação de atraso e o ganho de 1/16 garante uma redução considerável de taxa de ruído enquanto mantém a convergência dos valores calculados(SCHULZRINNE et al., 2003)(CADZOW, 1987).

Para exemplificar o cálculo da variação de atraso, alguns pacotes foram capturados de um roteador durante uma transmissão de mídia utilizando o protocolo RTP. Os valores dos campos sequência, chegada e timestamp do protocolo RTP e o cálculo da variação de atraso são mostrados na tabela 3.1.

\begin{tabular}{|c|c|c|c|c|c|}
\hline Pacote & Sequência & Chegada (Ri) & Timestamp (Si) & Diferença (D) & Jitter $(\mathrm{J})$ \\
\hline 1 & 55350 & 0.000000 & 540580046 & $0 \mathrm{~ms}$ & $0 \mathrm{~ms}$ \\
\hline 2 & 55351 & 0.000188 & 540580356 & $0.19 \mathrm{~ms}$ & $0.2 \mathrm{~ms}$ \\
\hline 3 & 55352 & 0.000492 & 540580665 & $0.3 \mathrm{~ms}$ & $0.39 \mathrm{~ms}$ \\
\hline 4 & 55353 & 0.004683 & 540580975 & $4.19 \mathrm{~ms}$ & $0.41 \mathrm{~ms}$ \\
\hline 5 & 55354 & 0.011586 & 540581285 & $6.9 \mathrm{~ms}$ & $0.6 \mathrm{~ms}$ \\
\hline 6 & 55355 & 0.011922 & 540581595 & $0.34 \mathrm{~ms}$ & $0.76 \mathrm{~ms}$ \\
\hline 7 & 55356 & 0.012239 & 540581905 & $0.32 \mathrm{~ms}$ & $0.9 \mathrm{~ms}$ \\
\hline 8 & 55357 & 0.014426 & 540582215 & $2.19 \mathrm{~ms}$ & $0.93 \mathrm{~ms}$ \\
\hline 9 & 55358 & 0.019360 & 540582525 & $4.93 \mathrm{~ms}$ & $0.96 \mathrm{~ms}$ \\
\hline 10 & 55359 & 0.028193 & 540582834 & $8.83 \mathrm{~ms}$ & $1.24 \mathrm{~ms}$ \\
\hline 11 & 55360 & 0.028480 & 540583144 & $0.29 \mathrm{~ms}$ & $1.36 \mathrm{~ms}$ \\
\hline 12 & 55361 & 0.028743 & 540583454 & $0.26 \mathrm{~ms}$ & $1.47 \mathrm{~ms}$ \\
\hline 13 & 55362 & 0.032035 & 540583764 & $3.29 \mathrm{~ms}$ & $1.39 \mathrm{~ms}$ \\
\hline 14 & 55363 & 0.037957 & 540584074 & $5.92 \mathrm{~ms}$ & $1.46 \mathrm{~ms}$ \\
\hline 15 & 55364 & 0.047562 & 540584384 & $9.61 \mathrm{~ms}$ & $1.75 \mathrm{~ms}$ \\
\hline 16 & 55365 & 0.047886 & 540584694 & $0.32 \mathrm{~ms}$ & $1.84 \mathrm{~ms}$ \\
\hline 17 & 55366 & 0.049467 & 540585004 & $1.58 \mathrm{~ms}$ & $1.84 \mathrm{~ms}$ \\
\hline 18 & 55367 & 0.055445 & 540585313 & $5.98 \mathrm{~ms}$ & $1.88 \mathrm{~ms}$ \\
\hline 19 & 55368 & 0.055732 & 540585623 & $0.29 \mathrm{~ms}$ & $1.96 \mathrm{~ms}$ \\
\hline 20 & 55369 & 0.056019 & 540585933 & $0.29 \mathrm{~ms}$ & $2.04 \mathrm{~ms}$ \\
\hline & & & & & \\
\hline
\end{tabular}

Tabela 3.1: Matriz para cálculo da variação de atraso (jitter)

A variação de atraso pode também ser calculada a partir de uma amostra de pacotes. Neste caso devemos calcular a média dos valores de Diferença (D) desta amostra. Esta será a alternativa utilizada na implementação do monitor RTP que será apresentado no capítulo de Validação da especificação e implementação. 


\subsubsection{Base de dados de engenharia de tráfego}

A Base de dados de engenharia de tráfego recebe informações consolidadas de QoS e dos equipamentos de rede do SGD com objetivo de prover ao HQoSB informações suficientes para que esta possa criar um modelo estatístico de rede. Com esses dados, o HQoSB deverá criar rotas que possuirão características favoráveis ao tipo de tráfego transportado e garantir QoS na entrega deste fluxo. A figura 3.3 mostra como - HQoSB pode mudar a configuração da rede com base nos dados armazenados na base de dados mandando mensagens, por exemplo, snmpset ${ }^{1}$ para os componentes da rede.

Neste capítulo foi apresentado a proposta do sistema de monitoramento no qual deve alimentar o sistema de controle de QoS, os subsistemas que o compõem e como, através dos campos do protocolo RTP, é possível obter parâmetros de qualidade de serviço de um fluxo de mídia em uma rede. No capítulo a seguir é demostrado o ambiente de validação construído com base nos conceitos apresentados neste capítulo.

\footnotetext{
${ }^{1}$ Mensagem snmp que modifica um valor na MIB
} 


\section{Validação da especificação e implementação}

Este capítulo apresenta os resultados experimentais alcançados pelo Sistema de Monitoramento de transmissão de TV Digital e compara os valores das perturbações de Qualidade de Serviço (variação de atraso e perda de pacotes) geradas em cada domínio com os valores da base de informações de gerência do Monitor RTP.

\subsection{Ambiente de validação}

O ambiente de validação foi construído com base na visão simplificada da arquitetura do sistema de monitoramento (figura 3.1). A partir desta aproximação foi possível criar um ambiente como mostrado na figura 4.1. Os Monitores RTP estão localizados em cada um dos domínios administrativos. Com isso foi possível obter os valores de variação de atraso, em todos os domínios, do fluxo de vídeo que atravessa rede.

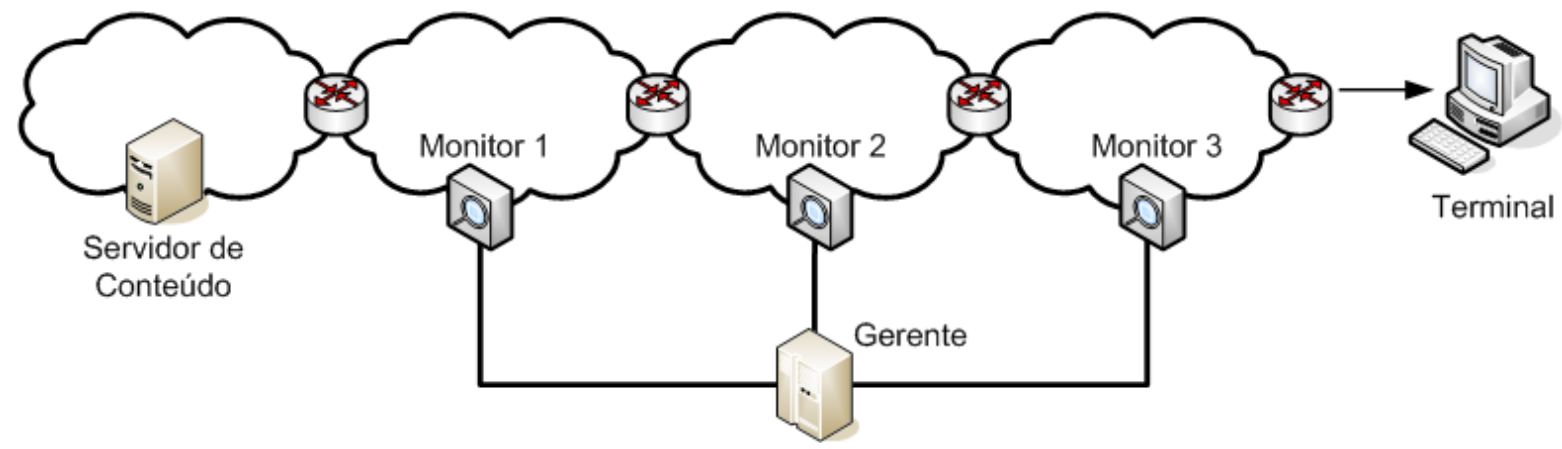

Figura 4.1: Distribuição dos Monitores RTP na topologia de rede simplificada

Esta topologia mostra que tanto em domínios administrativos diferentes como em roteadores do próprio domínio, o Gerente deste domínio é capaz de obter os valores de variação de atraso nos fluxos de vídeo. No caso de domínios administrativos distintos, 
- Gerente deve ser capaz de obter informações dos Monitores de outros domínios ou trocar informações com o Gerente deste domínio que se encontra o Monitor RTP.

Com base nesta aproximação, foi criado um ambiente de máquinas virtuais ${ }^{1}$ com 0 software VMware Server ${ }^{2}$. Este software permite que o usuário crie múltiplas máquinas virtuais e use uma ou mais dessas máquinas simultaneamente no mesmo sistema operacional local.

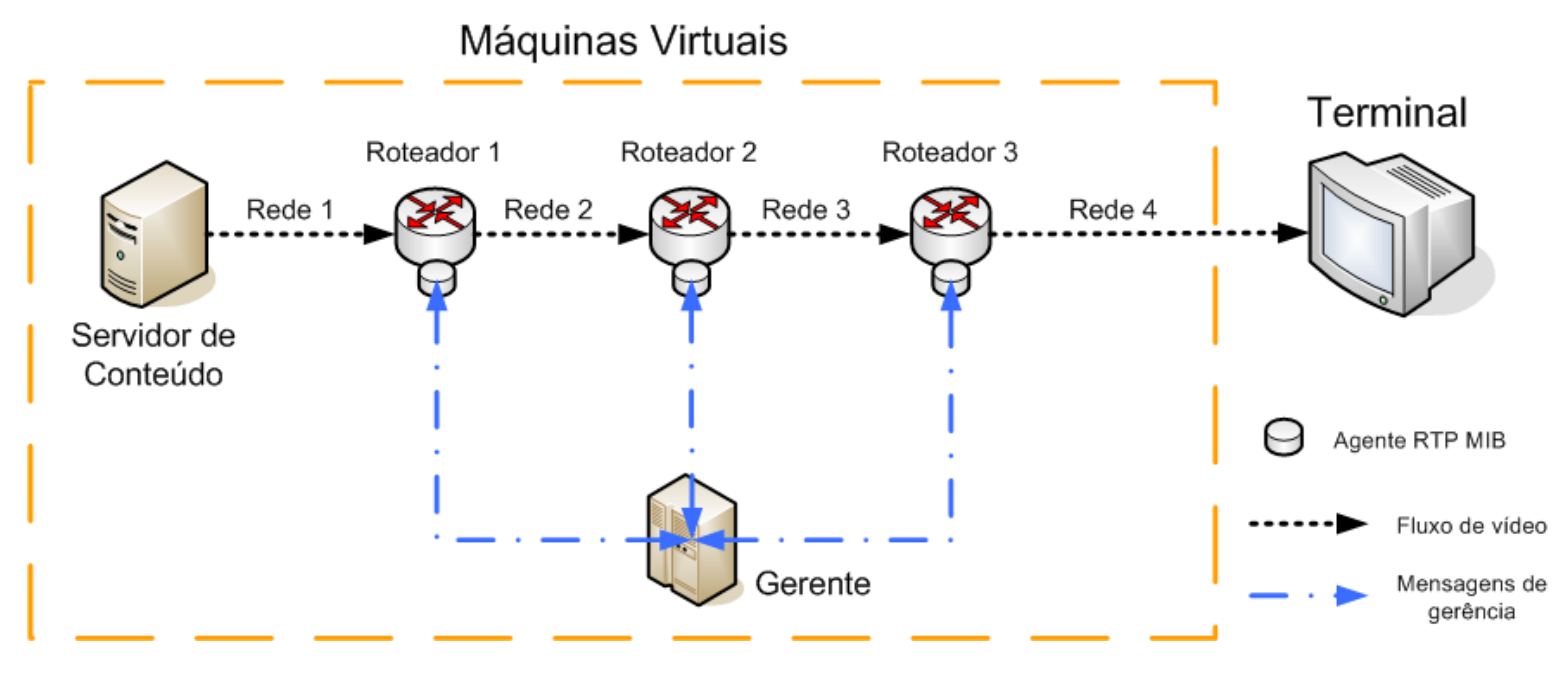

Figura 4.2: Ambiente de validação

A figura 4.2 mostra o ambiente de validação, onde o servidor de conteúdo, os roteadores e o gerente são emulados em máquinas virtuais (quadrado tracejado) enquanto que o terminal é a própria máquina local. Em cada um dos roteadores foi implementado um agente contendo uma MIB-RTP simplificada para obter valores de variação de atraso em cada uma das redes que os interconecta. Neste ambiente foi considerado somente a variação de atraso, valor que pode ser adquirido utilizando a MIB-RTP, os outros parâmetros relacionados à Qualidade de Serviço podem ser adquiridos de MIBs comuns e não serão abordados nesta validação. O fluxo de mídia é criado pelo servidor de conteúdo e atravessa todos os roteadores até chegar ao terminal do usuário.

O Gerente da rede é responsável por obter o valor da variação de atraso calculada pelos agentes instalados nos roteadores e alimentar a base de dados com o nível de Qualidade de Serviço de cada aplicação. Para esta finalidade foi utilizado o gerente

\footnotetext{
${ }^{1} \mathrm{Em}$ ciência da computação, uma máquina virtual é um software que cria um ambiente virtualizado entre a plataforma do computador e seu sistema operacional, assim o usuário pode executar um programa em uma máquina abstrata.

${ }^{2} \mathrm{O}$ VMware Server consiste em um conjunto de ferrramentas de virtualização para computadores $x 86$ e x86-64
} 
ZABBIX ${ }^{3}$ que através de mensagens SNMP obtém os valores de variação de atraso entre os roteadores e mostra os resultados através de uma interface web acessada pelo navegador da máquina local.

\subsection{Resultados da validação}

Para fazer a validação do sistema, foi iniciada uma transmissão de vídeo utilizando o protocolo RTP entre Servidor de Conteúdo e o terminal. Para este fim foi utilizado o programa VLC media player ${ }^{4}$, um software que pode ser utilizado para execução, transcodificação e transmissão de vídeo.

A primeira etapa de validação consistuiu em iniciar uma transmissão entre o Servidor de Conteúdo e o Terminal em uma rede sem perturbações, isto é, com valores de variação de atraso baixos, capturar os pacotes RTP que atravessa um dos roteadores, no caso do exemplo o Roteador 2, e calcular o valor médio e máximo de variação de atraso neste segmento.

A tabela 4.1 lista os valores obtidos dos campos timestamp e chegada do cabeçalho do protocolo RTP de 20 pacotes que atravessaram este roteador. Neste caso a rede está livre de perturbações que possam comprometer a Qualidade de Serviço. A última coluna mostra o valor calculado do Delta entre as chegadas de pacotes e com base nesses valores é calculado o valor médio e máximo de variação de atraso. Os valores de timestamp e chegada estão em ordem crescente, isto demonstra que não existiu desordenação de pacotes causada pela variação de atraso neste período. Neste primeiro exemplo o valor de variação de atraso médio ficou em $13.6 \mathrm{~ms}$ e a variação de atraso máxima $31.6 \mathrm{~ms}$.

A segunda etapa da validação consiste em obter os valores dos campos do protocolo RTP em uma rede com valores de variação de atraso alto. Esta perturbação é feita utilizando o Netem $^{5}$ e tem como objetivo validar o cálculo desta variação de atraso. Normalmente o atraso em uma rede não é uniforme, deste modo o Netem utiliza uma distribuição do tipo não uniforme de atraso por padrão. Isto faz com que os valores de

\footnotetext{
${ }^{3}$ Ferramenta em código aberto projetada para monitorar o estado de diversos serviços, servidores e outros hardwares de redes de computadores

${ }^{4} \mathrm{http}: / /$ www.videolan.org/

${ }^{5} \mathrm{NetEm}$ - Network Emulator é um aprimoramento das funcionalidades de controle de tráfego do Linux, pode ser utilizado para gerar perda de pacotes, atraso, variação de atraso (HEMMINGER, 2003).
} 


\begin{tabular}{|c|c|c|c|}
\hline Pacote & timestamp & chegada & Delta (ms) \\
\hline 1 & 170022489 & 9.839475 & 6.903362 \\
\hline 2 & 170025231 & 9.863038 & 16.034251 \\
\hline 3 & 170027972 & 9.877459 & 10.687638 \\
\hline 4 & 170030714 & 9.918613 & 30.393362 \\
\hline 5 & 170033456 & 9.918686 & 17.749638 \\
\hline 6 & 170036198 & 9.966902 & 8.862539 \\
\hline 7 & 170039049 & 10.007442 & 31.672223 \\
\hline 8 & 170046056 & 10.116969 & 0.115167 \\
\hline 9 & 170049559 & 10.156006 & 6.190056 \\
\hline 10 & 170053063 & 10.201129 & 18.918833 \\
\hline 11 & 170056566 & 10.221132 & 8.645242 \\
\hline 12 & 170060388 & 10.254953 & 22.560242 \\
\hline 13 & 170064210 & 10.274859 & 19.391242 \\
\hline 14 & 170068032 & 10.297934 & 11.064758 \\
\hline 15 & 170071854 & 10.351465 & 4.139859 \\
\hline 16 & 170075585 & 10.397060 & 25.421056 \\
\hline 17 & 170079089 & 10.461414 & 11.132167 \\
\hline 18 & 170082592 & 10.511468 & 1.953056 \\
\hline 19 & 170086096 & 10.552354 & 1.324167 \\
\hline 20 & 170089599 & 10.592600 & 20.296944 \\
\hline
\end{tabular}

Tabela 4.1: Valores dos campos do protocolo RTP sem perturbação na rede

Delta tenham uma variação grande quando há perturbação adicionada pelo Netem.

Os pacotes capturados são ordenados por timestamp e é feito o cálculo dos Deltas entre esses pacotes. A tabela 4.2 lista os valores obtidos dos campos timestamp e chegada do cabeçalho do protocolo RTP de 20 pacotes que atravessaram este segmento. Neste caso a rede está com perturbações introduzidas na interface de saída do Roteador 1 e são sentidas pelos demais roteadores e terminal. Diferentemente da tabela 4.1, os valores de chegada dos pacotes RTP não estão em ordem crescente, consequentemente conclui-se que existiu variação de atraso entre os pacotes desordenando-os. Neste segundo exemplo o valor de variação de atraso média ficou em 71.5 ms e a variação de atraso máxima 226.7 ms para uma variação de $100 \mathrm{~ms}$ introduzida pelo Netem.

Para que o sistema possa obter essas informações automaticamente foi criado um programa em $\mathrm{PERL}^{6}$ que captura e filtra os pacotes que utilizam o protocolo RTP. Esses pacotes são então adicionados a uma matriz e é feito o cálculo da variação de atraso. Além disso, o agente SNMP instalados em cada um dos roteadores foi configu-

\footnotetext{
${ }^{6}$ Perl é uma linguagem de programação dinamica criada por Larry Wall em 1987. Ela engloba funcionalidades de outras linguagens de programação incluindo C, shell scripting (sh) e AWK.
} 


\begin{tabular}{|c|c|c|c|}
\hline Pacote & timestamp & Chegada & Delta $(\mathrm{ms})$ \\
\hline 1 & 258755792 & 35.999715 & 10.520932 \\
\hline 2 & 258768404 & 36.129326 & 226.774644 \\
\hline 3 & 258772608 & 35.949262 & 10.391399 \\
\hline 4 & 258781017 & 36.032303 & 10.806644 \\
\hline 5 & 258785221 & 36.068207 & 99.999232 \\
\hline 6 & 258789309 & 36.213628 & 17.564659 \\
\hline 7 & 258793378 & 36.241274 & 62.713452 \\
\hline 8 & 258797446 & 36.349187 & 21.184659 \\
\hline 9 & 258801515 & 36.373213 & 137.487097 \\
\hline 10 & 258805642 & 36.281581 & 153.099356 \\
\hline 11 & 258809846 & 36.481391 & 6.775644 \\
\hline 12 & 258814050 & 36.521326 & 53.280356 \\
\hline 13 & 258818254 & 36.621317 & 75.224417 \\
\hline 14 & 258822501 & 36.593281 & 58.205945 \\
\hline 15 & 258827006 & 36.701542 & 94.090944 \\
\hline 16 & 258831510 & 36.657495 & 144.677945 \\
\hline 17 & 258836015 & 36.852228 & 92.651608 \\
\hline 18 & 258840543 & 36.809887 & 9.628481 \\
\hline 19 & 258845214 & 36.852158 & 19.639592 \\
\hline 20 & 258849886 & 36.884429 & 126.516481 \\
\hline
\end{tabular}

Tabela 4.2: Valores dos campos do protocolo RTP com perturbação na rede

rado para responder à requisições de valores da RTP-MIB calculados pelo programa em PERL. Com isso o gerente ZABBIX pôde construir uma interface com informações relativas à variação de atraso média (representada pela área preenchida do gráfico) e máxima (representada pela linha escura no gráfico) nos três roteadores da rede, como mostra a figura 4.3 .

Com essas configurações, foram introduzidas as seguintes perturbações nos três roteadores:

- No instante T0, foi adicionada à saída do Roteador 2 uma perturbação de variação de atraso de $150 \mathrm{~ms}$;

- No instante T1, as condições normais foram restauradas na saída do Roteador 2;

- No instante T2, foi adicionada à saída do Servidor de Conteúdo uma perturbação de variação de atraso de $100 \mathrm{~ms}$;

- No instante T3, as condições normais foram restauradas na saída do Servidor de Conteúdo; 


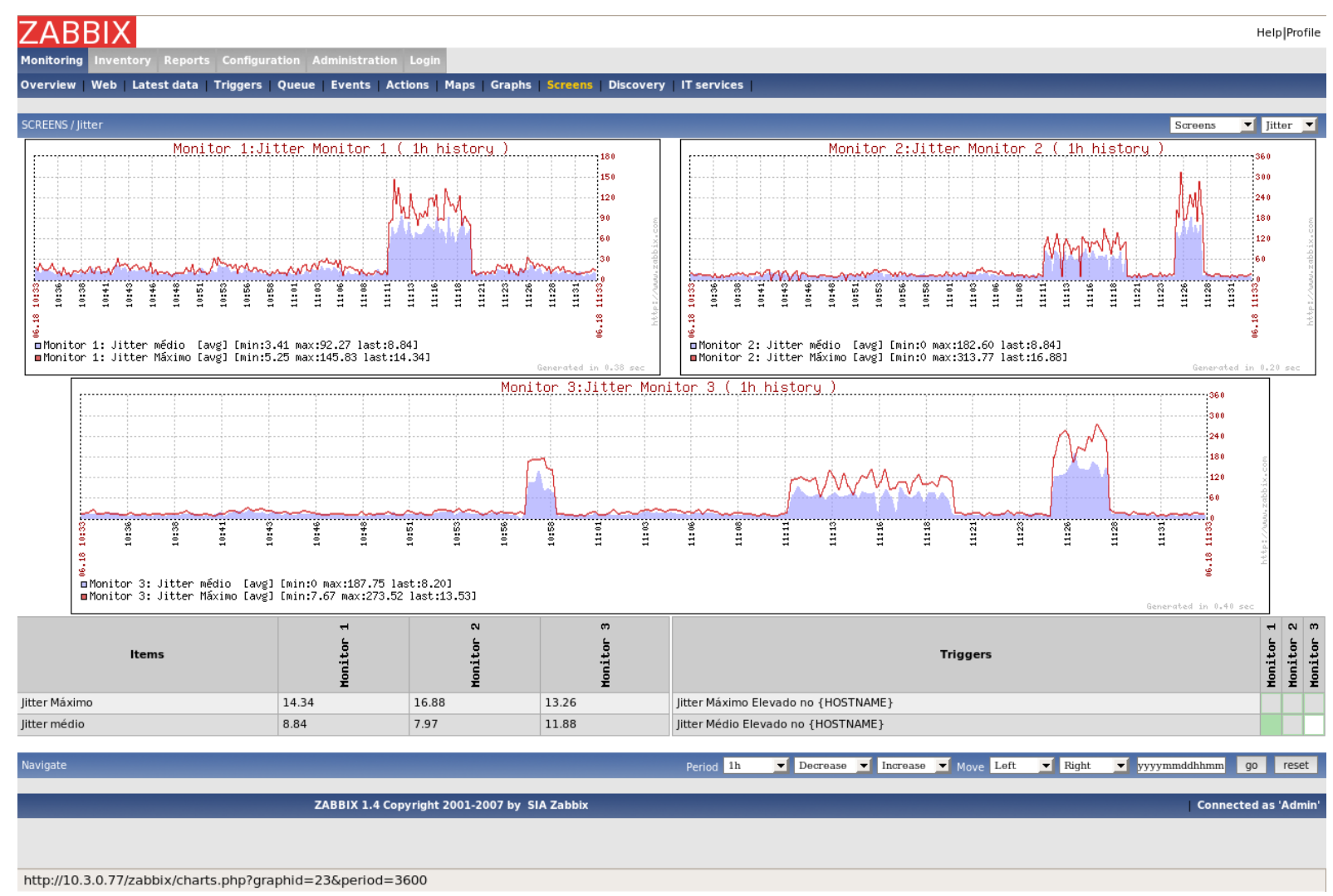

Figura 4.3: Interface web do Gerente com informações de variação de atraso

- No instante T4, foi adicionada à saída do Roteador 1 uma perturbação de variação de atraso de $200 \mathrm{~ms}$;

- No instante T5, as condições normais foram restauradas na saída do Roteador 1 ;

As figuras 4.4, 4.5 e 4.6, gerados pelo gerente mostram os valores de variação de atraso nos Roteadores 1, 2 e 3 respectivamente. O gráfico do primeiro roteador 4.4 mostra uma elevação de valores de variação de atraso média e máxima entre os instantes T2 e T3, este roteador, por ser o primeiro em que passa o fluxo, só sente as perturbações geradas pelo Servidor de Conteúdo.

O gráfico gerado através de dados obtidos do segundo roteador (figura 4.5) apresenta as perturbações geradas tanto no Servidor de Conteúdo quanto no Roteador 1. Neste caso os valores elevados no gráfico ocorrem entre os instantes T2 e T3 e também entre os instantes T4 e T5.

O gráfico gerado com base no variação de atraso no terceiro roteador (figura 4.6) mostra que, como este roteador recebe o fluxo que passou pelos outros dois roteado- 


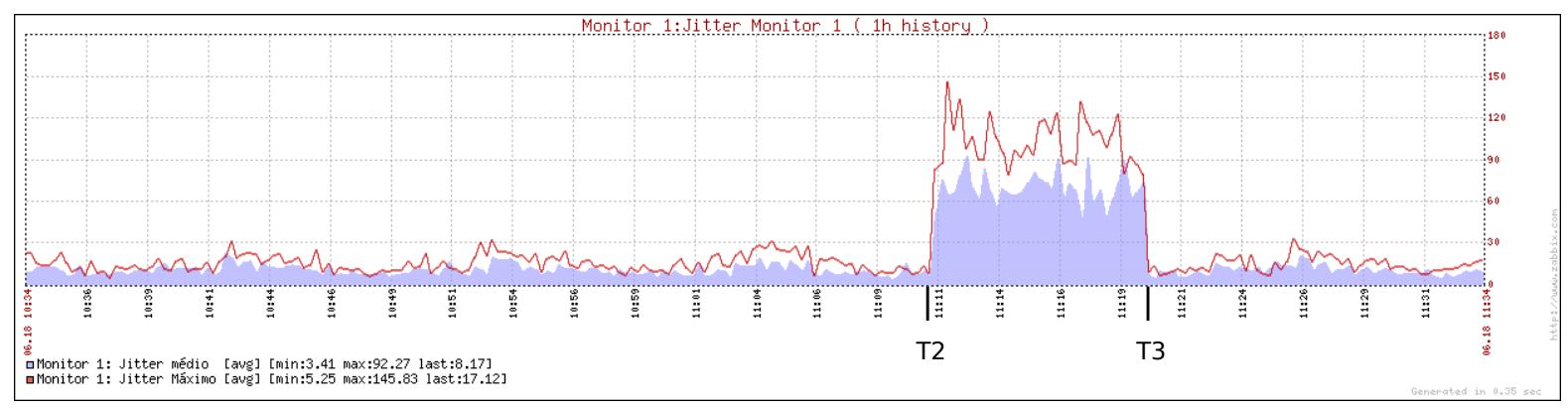

Figura 4.4: Gráficos de variação de atraso no Monitor 1

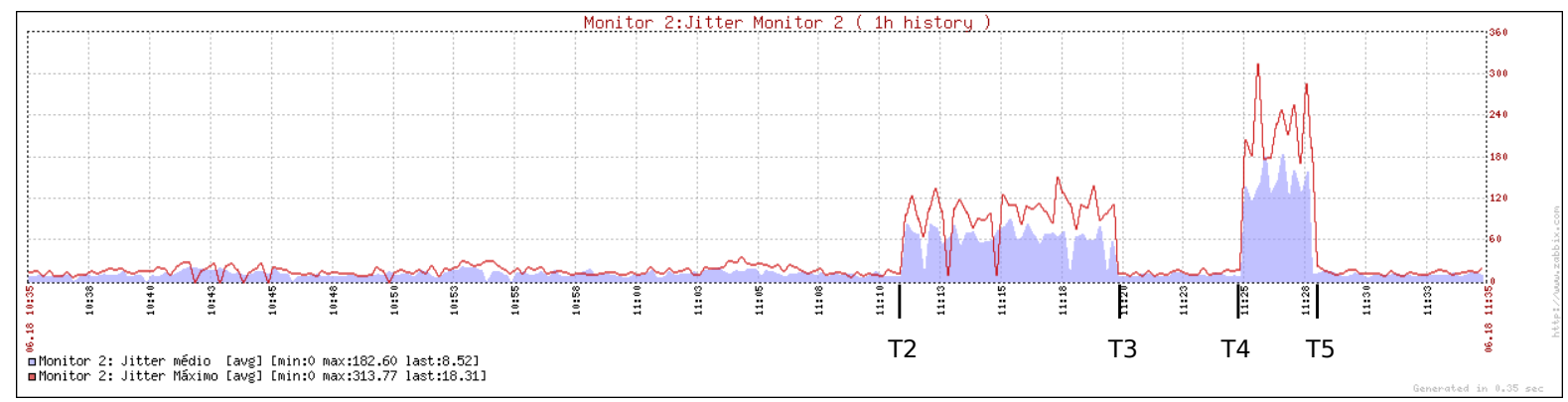

Figura 4.5: Gráficos de variação de atraso no Monitor 2

res, perturbação em três fases distintas. Entre os instantes T0 e T1, T2 e T3 e T4 e T5 podemos ver alteração do valor de variação de atraso que foram detectadas pelo Roteador 3.

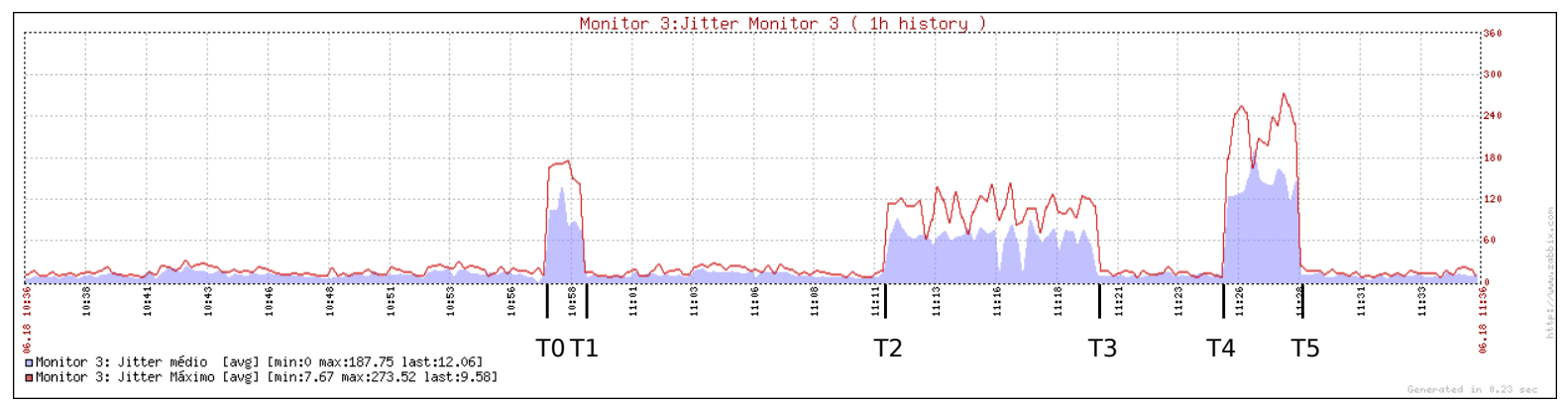

Figura 4.6: Gráficos de variação de atraso no Monitor 3

Através destes gráficos é possível definir os intervalos em que a rede sofreu perturbações de variação de atraso e com a coposição desses gráficos, é possível também determinar onde ocorreu a perturbação de Qualidade de Serviço na rede. 


\section{Conclusões}

A grande evolução nos sistemas de comunicação, relacionados à transmissão de conteúdo multimídia nas redes de comunicação de dados e de transmissão de TV, demanda soluções de gerência da qualidade de serviço fim a fim. Diante deste cenário foi proposto nesse trabalho a definição e implementação de uma solução para monitoramento de transmissão de mídia que permite ser aplicada em arquiteturas de redes modernas e antigas, padronizadas e proprietárias.

Para isso, foram discutidos aspectos fundamentais para o monitoramento de fluxo de TV Digital em redes heterogêneas. Inicialmente, foi apresentado um ambiente que possui a necessidade de monitoramento dos fluxos de TV Digital e, a partir deste ponto, foi possível traçar os requisitos de gerenciamento. Como solução foi selecionado o protocolo de transporte RTP, a partir da análise da pilha de protocolos de comunicação entre diversos subsistemas. Tal protocolo é responsável pela transmissão de mídias e sua base de informações de gerência (MIB-RTP) é utilizada para monitorar os fluxos de vídeo.

Para a implementação dessa solução foi definida uma arquitetura capaz de monitorar a transmissão de mídias envolvendo Sistemas de Gerenciamento de Domínio e Redes de Comunicação. Para validar esta arquitetura foi desenvolvido um protótipo, como prova de conceito, que permite obter resultados sobre a qualidade dos serviços trafegados entre os sistemas.

A análise, desenvolvimento, implementação e validação mencionadas permitiu gerar as contribuições detalhadas a seguir. 


\subsection{Contribuições}

São várias as contribuições relevantes com o desenvolvimento deste trabalho. Isto se observa tanto na identificação de necessidades, levantamento de requisitos e criação da arquitetura , como também na implementação do protótipo do sistema de monitoramento e sua validação.

A arquitetura de gerência de redes criada, utilizando o protocolo RTP é a mais importante contribuição. Para isso, foi feito uma análise dos principais tipos de rede que compõem um sistema de transmissão de TV Digital e avaliado quais das soluções de gerência existentes são mais utilizadas em cada uma dessas redes. A partir dessa análise a arquitetura SNMP de gerência de redes foi selecionada para ser implementada no sistema de monitoramento deste trabalho em função de se mostrar a mais utilizada atualmente pela maioria dos equipamentos de rede e aplicações, e conter uma base de informações de gerência específica para o protocolo RTP necessárias para o sistema implementado.

Como fundamental contribuição foi concebida a arquitetura do sistema para monitoramento de transmissão de TV Dlgital que dá subsidios à implementação do sistema em questão. Ela é constituída por quatro subsistemas (Subsistema de Gerenciamento de Domínio, subsistema de Controle de QoS, Monitor RTP e base de dados de engenharia de tráfego) que se integram entre si. O protocolo RTP e sua base de informações de gerência (MIB-RTP) mostraram-se capazes de criar um elemento chamado Monitor RTP que tem como principal característica calcular a variação de atraso dos pacotes dos fluxos de mídia. Deste modo, monitores RTP espalhados pela rede podem ser usados para diagnosticar problemas e identificar onde estes ocorrem. Através da implementação do Monitor RTP e configuração de um gerente SNMP foi possível implementar um sistema que permite determinar a variação de atraso nos pacotes do fluxo de TV Digital que atravessa a rede criando a possibilidade de monitorar requisitos de qualidade de serviço.

A implementação de um protótipo de validação e seus resultados foi uma segunda contribuição importante, permitindo colher resultados sobre as condições da rede em análise. Assim, um ambiente de máquinas virtuais que emulam a interligação de quatro domínios administrativos de rede diferentes, de acordo com a topologia de rede apresentada no capítulo 2. A partir deste ponto, utilizando uma ferramenta de transmissão de vídeo pelo protocolo RTP e introduzindo perturbações de variação de 
atraso, os Monitores RTP posicionados dentro de cada domínio administrativo mostraram como resultados valores médio e máximo de variação de atraso dos fluxos da rede analisada.

Por fim, outra contribuição a ser observada é a análise detalhada dos componentes do sistema de TV Digital de uma rede heterogênea que integra cinco subsistemas principais. Para a seleção do protocolo de transmissão RTP foi analisada a pilha de protocolos de comunicação entre os subsistemas Criação de Conteúdo, Servidor de Serviços, Antena e Terminal.

O conjunto dessas contribuições gera um sistema capaz de gerenciar ambientes que envolvem redes independente da infra-estrutura de comunicação criando possibilidade de obter informações de variação de atraso de mídias caracterizadas como sensíveis. Estas informações levam o observador à identificar o estado da rede permitindo inclusive gerar alertas futuramente.

\subsection{Trabalhos Futuros}

O desenvolvimento do sistema de monitoramento permitiu verificar algumas funcionalidades e melhorias, além da integração de novos componentes, que podem ser futuramente incluídas neste trabalho.

Uma delas seria a implementação de aplicativos de diagnóstico a partir dos dados armazenados na estrutura de dados criada pelo gerente ZABBIX. Tal implementação deverá prover informações sobre condições na rede capazes de resolver previamente questões como alocação de recursos em redes com problemas de QoS.

Uma lacuna deixada no desenvolvimento do sistema de monitoramento é a extensão do Monitor RTP para obtenção de outros parâmetros de qualidade de serviço como taxas de ocupação de enlaces entre domínios, bem como perda de pacote. Estes parâmetros permitem a ampliação das informações que medem o desempenho e o nível de QoS da rede tornando o sistema aqui implementado mais abrangente.

Este trabalho dá subsídios para ampla utilização do sistema de monitoramento desenvolvido criando possibilidades de integração com outras ferramentas capazes de 
sofisticar o ambiente de gerência de redes. Ferramentas de diagnóstico capazes de avaliar as condições de uma rede poderiam ser melhoradas através da inclusão de novos parâmetros de QoS gerados pelo sistema desenvolvido neste trabalho. Além disso, a integração com o Sistema de Controle de QoS da arquitetura apresentada permite validar a solução completa do projeto INSTINCT. A alimentação desse sistema com os dados obtidos pelo sistema de monitoramento desenvolvido, permitiriam gerar resultados capazes de definir prioridades de pacotes da rede bem como definir rotas otimizadas.

Outra integração que traria benefícios ao sistema implementado seria com sistemas de SLMs (Sevice Level Management). Tal integração permitiria que as informações geradas pelo sistema proposto e acopladas ao SLM notificassem sistemas de gerenciamento quando níveis de SLA (Service Level Agreement) atingissem valores indesejáveis. 


\section{Referências Bibliográficas}

SHULZYCKI, A. 'DTT in Europe: market overview and assessment. DigiTAG Exploratory Meeting, European Broadcasting Union, Geneva, September, 2003.

GABOS, D. et al. Instinct deliverable 7.3 - definition of the instinct architecture and protocols for a brazilian environment and a qos convergent network evaluation tool specification. 2006.

ANNEGARN, M. et al. HD-MAC: A step forward in the evolution of television technology. PHILIPS TECH. REV., v. 43, n. 8, p. 197-212, 1987.

FARIA, G. et al. DVB-H: Digital Broadcast Services to Handheld Devices. Proceedings of the IEEE, v. 94, n. 1, p. 194-209, 2006.

MITCHELL, J. L. et al. MPEG Video Compression Standard. NY, USA: Chapman and Hall, 2002.

BERG, M. Instinct deliverable 7.1 - description of the fixed support infrastructure in instinct. 2004.

BRADEN, B.; CLARK, D.; SHENKER, S. Integrated Service in the Internet Architecture: An Overview. 1994.

EVAIN, J. The Multimedia Home Platform. EBU Technical Review, v. 275, p. 4-10, 1998.

MILENKOVIC, M. Delivering interactive services via a digital TV infrastructure. Multimedia, IEEE, v. 5, n. 4, p. 34-43, 1998.

SCHAFER, R. The status of HDTV in Europe. Communications Magazine, IEEE, v. 34, n. 6 , p. $120-125,1996$.

HEINE, G. GSM Networks. 1st.. ed. [S.I.]: Artech House Mobile Communications Library, 1999.

TANENBAUM, A. Redes de computadores. [S.I.]: Campus, 1997.

HASKELL, B.; PURI, A.; NETRAVALI, A. Digital Video:: an Introduction to MPEG-2. [S.I.]: NetLibrary, Incorporated, 2002.

WECK, C. Coverage aspects of digital terrestrial television broadcasting. EBU Technical Review, v. 270, p. 19-30, 1996.

SCHULZRINNE, H. et al. RFC1889: RTP: A Transport Protocol for Real-Time Applications. Internet RFCs, RFC Editor United States, 1996. 
SCHULZRINNE, H. et al. 3550:"RTP: A Transport Protocol for Real-Time Applications. IETF, RFC, 2003.

PERKINS, C. RTP: Audio and Video for the Internet. [S.I.]: Addison-Wesley Professional, 2003. Hardcover. ISBN 0672322498.

FRASER; ONUFRYK; RAMAKRISHNAN. Encapsulation of Real-Time Data Including RTP Streams over ATM. Included in H, v. 323, 1998.

CARVALHO, T. Gerenciamento de Redes: uma abordagem de sistemas abertos. Rio de Janeiro, Brasil: BRISA, Makron Books, Telebrás, 1993.

STALLINGS, W. Snmp and snmpv2: The infrastructure for network management. IEEE Communication Magazine, v. 36, n. 3, 1998.

SUN MICROSYSTEMS. Java Management Extensions. http://www.sun.com, 2006.

DITTRICH, A. Corba: Integrating diverse applications within distributed heterogeneous environments. IEEE Communication Magazine, v. 14, February 1997.

THOMPSON, J. Web-based enterprise management architecture. Communications Magazine, IEEE, v. 36, n. 3, p. 80-86, 1998.

BAUGHER, M. et al. Real-Time Transport Protocol Management Information Base. http://www.ietf.org/internet-drafts/draft-ietf-avt-rtp-mib-05.txt, 1999.

BAUGHER, M.; STRAHM, B.; SUCONICK, I. Real-time transport protocol management information base, Internet Engineering Task Force (IETF). [S.I.], 2000.

BACHER, D.; SWAN, A.; ROWE, L. rtpmon: a third-party RTCP monitor. Proceedings of the fourth ACM international conference on Multimedia, ACM Press New York, NY, USA, p. 437-438, 1997.

CADZOW, J. Foundations of digital signal processing and data analysis. [S.I.]: Collier Macmillan London, 1987.

HEMMINGER, S. Netem-emulating real networks in the lab. Proc. Linux Conference Australia, 2003. 